Article

\title{
On the Potential of RST-FLOOD on Visible Infrared Imaging Radiometer Suite Data for Flooded Areas Detection
}

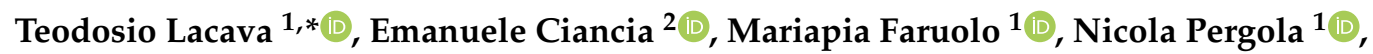 \\ Valeria Satriano ${ }^{1}$ and Valerio Tramutoli ${ }^{2}$ (D) \\ 1 National Research Council, Institute of Methodologies for Environmental Analysis, C. da S. Loja, \\ 85050 Tito Scalo (PZ), Italy; mariapia.faruolo@imaa.cnr.it (M.F.); nicola.pergola@imaa.cnr.it (N.P.); \\ valeria.satriano@imaa.cnr.it (V.S.) \\ 2 University of Basilicata, School of Engineering, Via dell'Ateneo Lucano, 10, 85100 Potenza, Italy; \\ emanuele.ciancia@imaa.cnr.it (E.C.); valerio.tramutoli@unibas.it (V.T.) \\ * Correspondence: teodosio.lacava@imaa.cnr.it; Tel.: +39-0971427242; Fax: +39-0971427205
}

Received: 13 February 2019; Accepted: 7 March 2019; Published: 12 March 2019

\begin{abstract}
Timely and continuous information about flood spatiotemporal evolution are fundamental to ensure an effective implementation of the relief and rescue operations in case of inundation events. In this framework, satellite remote sensing may provide a valuable contribution provided that robust data analysis methods are implemented and suitable data, in terms of spatial, spectral and temporal resolutions, are employed. In this paper, the Robust Satellite Techniques (RST) approach, a satellite-based differential approach, already applied at detecting flooded areas (and therefore christened RST-FLOOD) with good results on different polar orbiting optical sensors (i.e., Advanced Very High Resolution Radiometer - AVHRR - and Moderate Resolution Imaging Spectroradiometer MODIS), has been fully implemented on time series of Suomi National Polar-orbiting Partnership (Suomi-NPP-SNPP) Visible Infrared Imaging Radiometer Suite (VIIRS) data. The flooding event affecting the Metaponto Plain in Basilicata and Puglia regions (southern Italy) in December 2013 was selected as a case study and investigated by analysing five years (only December month) of VIIRS Imagery bands at $375 \mathrm{~m}$ spatial resolution. The achieved results clearly indicate the potential of the proposed approach, especially when compared with a satellite-based high resolution map of flooded area, as well as with the official flood hazard map of the area and the outputs of a recent published VIIRS-based method. Both flood extent and dynamics have been recognized with good reliability during the investigated period, with only a residual $11.5 \%$ of possible false positives over an inundated area extent of about $73 \mathrm{~km}^{2}$. In addition, a flooded area of about $18 \mathrm{~km}^{2}$ was found outside the hazard map, suggesting it requires updating to better manage flood risk and prevent future damages. Finally, the achieved results indicate that medium-resolution optical data, if analysed with robust methodologies like RST-FLOOD, can be suitable for detecting and monitoring floods also in case of small hydrological basins.
\end{abstract}

Keywords: flood; satellite remote sensing; near real time; RST-FLOOD; SNPP; JPSS; VIIRS

\section{Introduction}

Among natural hazards, floods are currently the most frequent and costliest [1], causing worldwide fatalities as well as huge economic damage, affecting both rural and urban environments [2]. For instance, in 2017, 47\% of the economic losses due to natural catastrophes were specifically related to floods (including both river flooding and flash floods) and another $35 \%$ to meteorological (i.e., storms) events [3]. Moreover, flood risk and the associated losses are projected to significantly increase in the 
future due to both human activities (i.e., land use/cover changes, new infrastructures construction, etc.) and natural causes (i.e., the effects of climate change, subsidence, etc.) $[2,4,5]$. To reduce the effects of these potential threats, effective flood risk management is required [2] as well as, in case of disaster, a prompt detection of flooded areas in order to support decision makers with relief and rescue operations [6]. In this framework, satellite remote sensing data have become a powerful tool, thanks to the growing availability of several satellite/sensors systems able to provide different information about inland surface water presence useful to manage flooding events $[7,8]$.

Microwave sensors can provide useful evidence (i.e., 24 hours and under cloudy conditions) about flooded areas, with different characteristics depending on the specific technology used [9]. Active systems, such as Synthetic Aperture Radar (SAR), can furnish data at a high spatial resolution (up to few meters) but, generally, with a long revisit period (up to five to six days), hence often resulting not suitable for assuring a quick identification and a continuous monitoring of flood-inundated area $[10,11]$. Their capabilities greatly improve when national space agencies focus the acquisitions of their satellites on the affected area or when specific services, such as the International Charter Space and Major Disasters [12] or the Copernicus Emergency Management [13] are activated. On the other hand, passive microwave sensors allow acquiring data with a poor spatial resolution (up to tens of kilometres) but with a high temporal frequency (up to few hours), especially if considering those instruments on board of polar weather satellites constellation [14]. Their spatial and temporal resolution makes these sensors particularly suitable for studying large-scale floods [6] but less adequate in case of moderate/small size events.

Optical sensors, acquiring data in the visible (VIS), near infrared (NIR) and shortwave infrared (SWIR) bands, allow for the detection of flooded areas during daytime and in absence of clouds $[7,10]$. The spatial resolution of these data ranges from few to hundreds of meters while the temporal resolution from some hours to a few days [10,15-17]. Therefore, in order to ensure continuous and near real time information in daytime conditions about flood dynamics, optical sensors onboard weather polar satellites represent one of the most suitable solution in furnishing useful data, in terms of both spatial, spectral and temporal resolutions [18]. Furthermore, considering that both optical and microwave sensors are often present on these satellites, their integration is an added value in providing a more comprehensive overview of the ongoing phenomena [6,18-20].

In the last years, optical data acquired by the Advanced Very High Resolution Radiometer (AVHRR) and Moderate Resolution Imaging Spectroradiometer (MODIS) have been analysed by implementing the Robust Satellite Technique (RST) [21] for detecting flooded areas and therefore christened RST-FLOOD, with satisfactory results [22,23]. In this paper, RST-FLOOD has been applied to Suomi National Polar-orbiting Partnership (Suomi-NPP) (SNPP) Visible Infrared Imaging Radiometer Suite (VIIRS) imagery to analyse the flooding event which hit the Basilicata and Puglia regions (southern Italy) in the first week of December 2013. The main objective of this work is to assess the potential of the developed RST-FLOOD scheme, when implemented on VIIRS Imagery (at $375 \mathrm{~m}$ of spatial resolution) bands, to get useful and reliable information for small-scale flood events.

\section{The Test Case}

The selected Region of Interest (ROI) is the Metaponto plain area, located between the south-eastern corner of the Basilicata Region (southern Italy) and a subset of the Puglia Region (Figure 1). This plain is of particular socio-economic and environmental importance for the region and interested by degradation processes mainly linked to land management and soil characteristics [24,25]. The area encloses the terminal sector of all the main Basilicata river basins, namely Sinni, Agri, Cavone, Basento and Bradano and of the Lato River, the major one of the Puglia Region (Figure 1). 


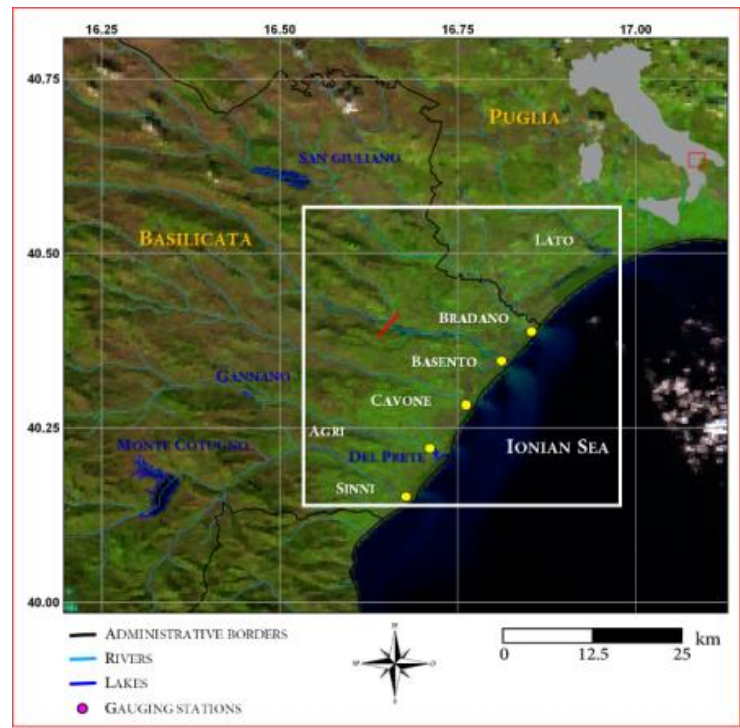

Figure 1. Localization of the Region of Interest (red box, in WGS-84 lat-long projection). In background the RGB False Colour (Red = Shortwave Infrared, namely I3 VIIRS band; Green = Near Infrared, namely I2 VIIRS band; Blue = RED, namely I1 VIIRS band) of VIIRS Imagery data acquired on 4 December 2013 at 12.10 GMT. Yellow dots indicate the localization of gauging stations along the five main rivers reaching the Ionian coast. The red segment and the white box will be used in the text.

All these rivers are strongly seasonal dependent, with maximum hydrometric levels recorded in winter and minimum in the summer [26]. The annual minimum flow rate of the Sinni and Agri rivers, whose basins are those mostly affected by precipitations at regional level, is 1.38 and $0.5 \mathrm{~m}^{3} / \mathrm{s}$, respectively [27]. Lower values are instead recorded for the Bradano and Basento rivers (i.e., 0.04 and $0.08 \mathrm{~m}^{3} / \mathrm{s}$ ), while Cavone River flow rate is practically nil [27]. The river levels are registered by the Civil Protection Department of Basilicata Region [28], by means of the five gauging stations (depicted by yellow dots in Figure 1) positioned close to the river mouths (i.e., within the Metaponto Plain), at the intersection with the freeway of the Basilicata region called "StradaStatale 106." Based on the temporal range when water levels were available (January 2011-September 2016), the three maxima measured at the five gauging stations and the corresponding dates are reported in Table 1, where they are listed from the highest to the lowest.

Table 1. The three maximum water levels (listed in decreasing order) measured in the period 01/01/2011-30/09/2016 and the corresponding dates for the Sinni, Agri, Cavone, Basento and Bradano rivers [28]. Note that for Agri River, data are available only for the period 01/01/2013-30/09/2016.

\begin{tabular}{cccccc}
\hline & Sinni & Agri & Cavone & Basento & Bradano \\
\hline & $3.59 \mathrm{~m}$ & $4.19 \mathrm{~m}$ & $5.22 \mathrm{~m}$ & $7.92 \mathrm{~m}$ & $6.04 \mathrm{~m}$ \\
& $01 / 12 / 2013$ & $01 / 12 / 2013$ & $04 / 02 / 2014$ & $02 / 12 / 2013$ & $02 / 03 / 2011$ \\
\cline { 2 - 5 } Max River & $3.47 \mathrm{~m}$ & $3.93 \mathrm{~m}$ & $5.00 \mathrm{~m}$ & $7.81 \mathrm{~m}$ & $5.39 \mathrm{~m}$ \\
Level Date & $28 / 03 / 2015$ & $13 / 03 / 2016$ & $02 / 12 / 2013$ & $03 / 12 / 2013$ & $02 / 12 / 2013$ \\
\cline { 2 - 6 } & $3.46 \mathrm{~m}$ & $3.55 \mathrm{~m}$ & $4.81 \mathrm{~m}$ & $7.60 \mathrm{~m}$ & $4.83 \mathrm{~m}$ \\
& $23 / 02 / 2012$ & $02 / 12 / 2013$ & $19 / 02 / 2011$ & $02 / 03 / 2011$ & $03 / 12 / 2013$ \\
\hline
\end{tabular}

Looking at the data in Table 1 it is worth noting an evident increase in the water level of all the rivers during the first week of December 2013 (Figure 2), which suggests the occurrence of an extreme hydrological event. The "Ciclone Nettuno" storm hit the Basilicata Region between 30 November and 3 December 2013, producing heavy convective precipitation [29,30]. A daily precipitation value of $130 \mathrm{~mm}$ was recorded on 1 December at the Bradano River gauging station, with a cumulative 
one of $200 \mathrm{~mm}$ for the entire event [31], indicating the strong intensity of this meteorological event. The consequent flooding event affected not only the Metaponto Plain in the Basilicata Region but also some areas in Puglia, where the Lato River overflowed near Castellaneta Marina, causing the closure of the freeway "Strada Statale 106" and severe damage to the surrounding lands and villages [28,32-36].

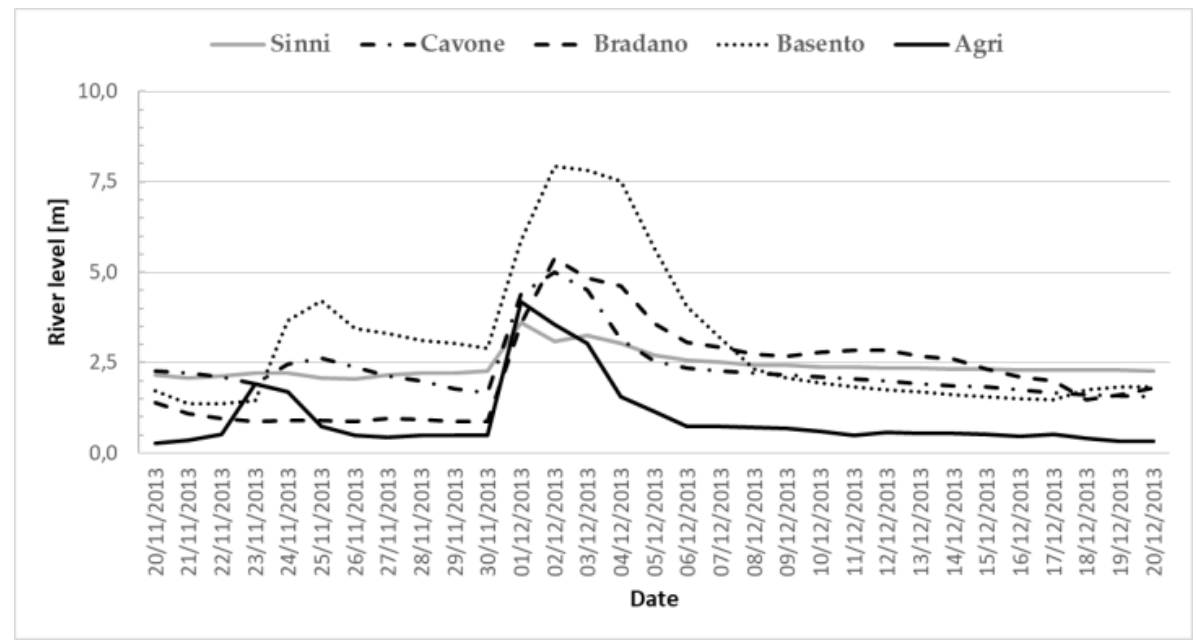

Figure 2. Basilicata river levels measured in the period 20/11/2013-20/12/2013 at the correspondent gauging stations indicated in Figure 1 [28].

This event has been already investigated by Reference [31], which, by integrating multi-temporal COSMO Sky MED SAR intensity images and interferometric-SAR coherence data with geomorphic and other ground information within a Bayesian network, detected flooded area, reaching accuracies of up to $89 \%$, in the 2-3 December 2013 period focusing on a small subset of Figure 1 centred on the Bradano River mouth. [37] extended the work of Reference [31] adding to the two above-mentioned COSMO Sky Med SAR imagery a Plèiades-1B High-Resolution data of 5 December 2013 to investigate a limited portion of Figure 1 centred on the Basento River mouth. SAR data were processed and used as in Reference [31] to identify flooded area on the above-mentioned days, while the Normalized Difference Vegetation Index (NDVI) was implemented on the Plèiades image to highlight water presence at the end of the event. A visual interpretation of the optical data combined with a field campaign allowed inferring information about results uncertainties [37]. Concerning the selected test case, the integration of outcomes of these two previous works gives an overview of the flood effects in a very small area (e.g., about $20 \mathrm{~km}^{2}$ ) and for a short temporal range (up to four days).

The approach proposed in this work should allow for both the extension of the spatiotemporal domain of the investigation of the event and the deep analysis of the phenomenon, thanks to the large swath as well as the continuity of observation ensured by sensors on-board polar satellites, like VIIRS.

\section{Data and Methods}

\subsection{VIIRS Data}

The VIIRS sensor is currently operational onboard SNPP (since October 2011) and the US Joint Polar Satellite System 1 (JPSS-1 or NOAA-20, since November 2017). In addition, three more VIIRS sensors will fly on the follow-on JPSS2-JPSS4 satellites, planned for launch from 2021 to 2031 [38,39] assuring an operational continuity like the one already offered by AVHHR and MODIS, namely its predecessors. Thanks to its large swath (i.e., $3060 \mathrm{~km}$ ), VIIRS has been providing a daily full Earth coverage [40], collecting data in 22 different spectral bands of the electromagnetic spectrum, ranging from $0.412 \mu \mathrm{m}$ and $12.01 \mu \mathrm{m}$, with a spatial resolution of $750 \mathrm{~m}$ at the nadir for both the Day/Night panchromatic Band (DNB) and the 16 Moderate resolution bands (M-bands) and of $375 \mathrm{~m}$ for the 5 high-resolution Imagery bands (I-bands) [40] . 
In this work, the following I-bands, namely I1 (0.60-0.68 $\mu \mathrm{m}, \mathrm{RED}), \mathrm{I} 2(0.85-0.88 \mu \mathrm{m}$, Near Infrared -NIR), I3 (1.58-1.64 $\mu \mathrm{m}$, Shortwave Infrared-SWIR) and I5 (10.5-12.4 $\mu \mathrm{m}$, Thermal Infrared-TIR) acquired in the month of December from 2013 to 2017 (for a total of 171 SNPP orbits) were analysed. In addition, the I-band terrain-corrected geolocation data (GITCO), including longitude, latitude, solar zenith angles, solar azimuth, sensor zenith and sensor azimuth angles, were also exploited. The I1-I3 data were converted in reflectance (R) values, while those related to I5 band in brightness temperature (BT).

In more detail, SNPP Sensor Data Record (SDR) data, directly acquired at the satellite receiving station of the Institute of Methodology for Environmental Analysis (IMAA) located in Tito Scalo (Basilicata region, southern Italy), have been processed by running the Community Satellite Processing Package (CSPP). Furthermore, SDR data were downloaded from NOAA CLASS archive [41] to fill any gaps within the considered historical series. The Polar2Grid v2.2 software [42] allowed the SDR spatial sub-setting over the ROI.

A total of 684 VIIRS SDR data was collected for the study area of $601 \times 600$ pixels, shown in Figure 1. The cloud-free VIIRS daytime imagery of the event, acquired on 4,5,6,7 and 8 December 2013, at 12.10 GMT, 11.52 GMT, 11.35 GMT, 11.12 GMT and 12.36 GMT, respectively, have been processed in terms of RST-FLOOD to analyse the above mentioned flooding event.

\subsection{Ancillary Data}

The reliability of the RST-FLOOD results has been assessed by means of a high resolution map, carried out applying a change detection scheme to a Landsat 7 (Enhanced Thematic Mapper Plus) ETM+ data (Figure 3) and the flood hazard maps provided, for the studied area, by the Italian Ministry of the Environment and Land Protection [43] (Figure 4). In addition, the sensitivity of the achieved outcomes has been evaluated for comparison with the outputs of the VIIRS NOAA\&GMU Flood Version 1.0 (VNG Flood V1.0, hereafter VNG) software, recently distributed in the framework of the CSPP network [44] (Figure 5).

Two Landsat 7 ETM+ (scene of $2534 \times 3400$ pixels, at $30 \mathrm{~m}$ of spatial resolution) images provided over the ROI with a higher spatial resolution then VIIRS ones, have been used to evaluate the flood detection results. In detail, the Landsat 7 ETM+ images acquired on 5 December 2013, at 9.31GMT and 24 December 2014, at 9.33 GMT were combined in a change detection scheme to highlight the flooded area. The Landsat Level-1 data, downloaded from USGS Earth Explorer Earth website [45], are distributed as scaled and calibrated digital numbers (DN). In this work, the DNs were converted to calibrated TOA (Top Of Atmosphere) reflectances using metadata which are distributed with the product. In Figure 3a,b the false colour composite images $(\mathrm{R}=$ Band 7, SWIR, 2.09-2.35 $\mu \mathrm{m}$; $\mathrm{G}=\mathrm{Band}$ 5, SWIR, 1.55-1.75 $\mu \mathrm{m}$; B = Band 1, RED, 0.63-0.69 $\mu \mathrm{m}$ ) of the analysed imagery are shown. The 753 combination provides a "natural-like" rendition, where flooded areas should look very dark blue or black [46]. Looking at the images, the presence of a large number of blue pixels is evident for the one acquired concurrently with the 2013 flood event (Figure 3a), while the other should more reflect the unperturbed condition. Besides, for each image, three maps were produced: RED - SWIR (B3 - B5), RED/SWIR (B3/B5) and their normalized difference (NDSI = RED-SWIR, RED/SWIR, B3 B5/B3 + B5), which all should be affected by a variation in surface water presence, as better discussed later (see Section 3.3). The "water affected areas," shown in magenta in Figure 3c (re-projected at $375 \mathrm{~m}$, for the comparison with RST-FLOOD results), is the "and" combination of the detections carried out integrating these three maps. By this approach, an area of about $24 \mathrm{~km}^{2}$ has been estimated as flooded affected, mostly localized along the Basento, Bradano and Lato rivers. Such a value is likely underestimated because of a number of issues regarding Landsat data [47], like the presence of data gaps towards the edges of the images due to the striping caused by the failure of the Landsat-7 ETM+ scan line corrector (SLC) in 2003. 

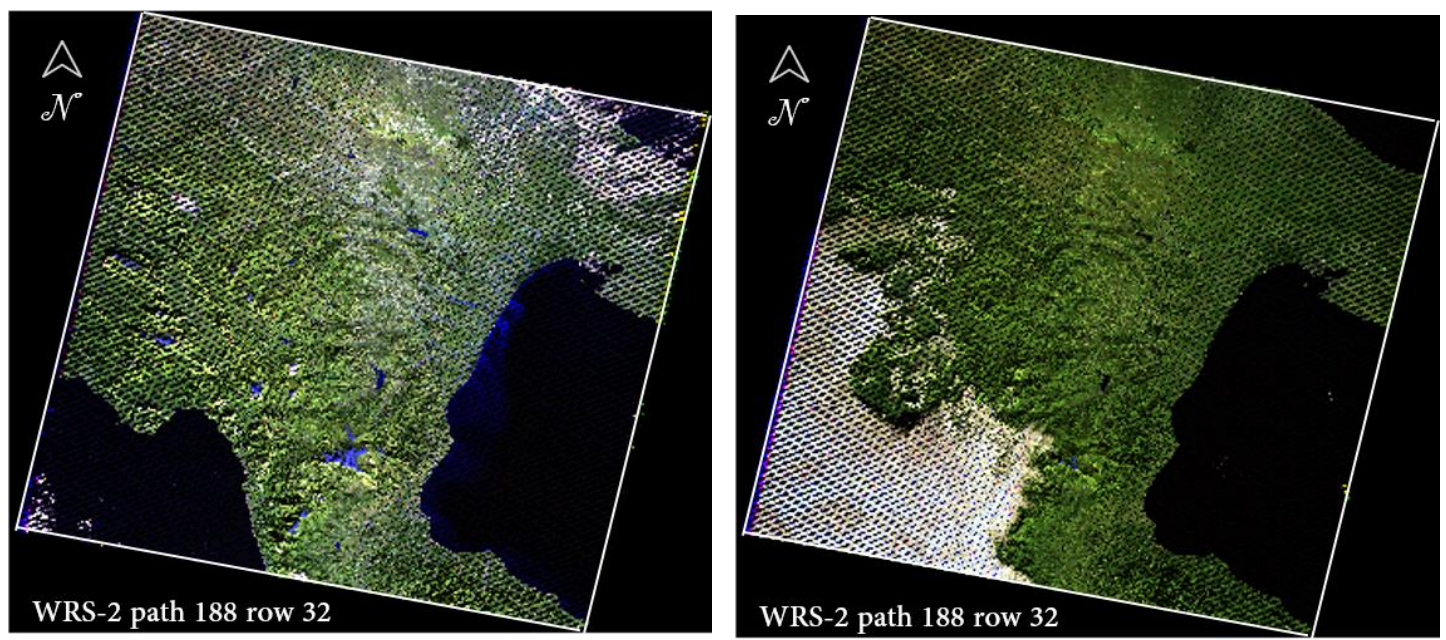

(a)

(b)

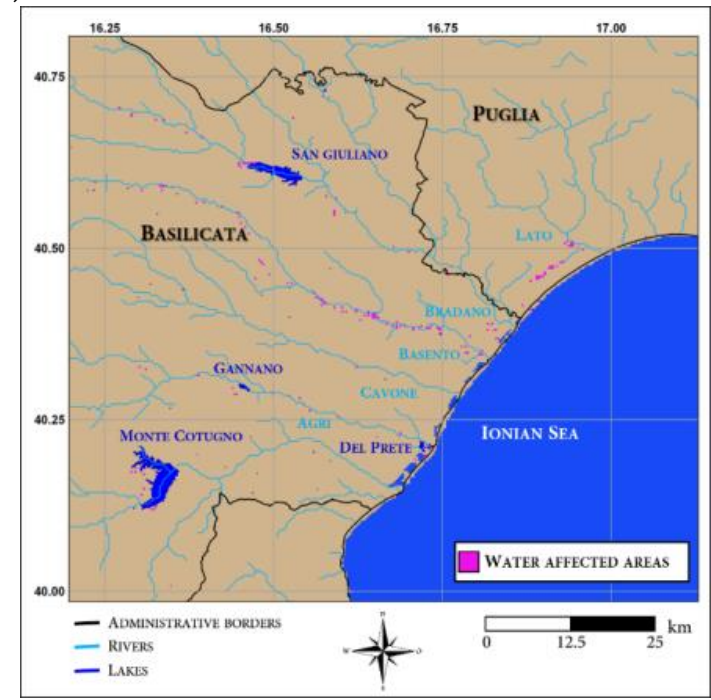

(c)

Figure 3. The Landsat 7 ETM+ false-colour $(R=$ Band 7, Shortwave Infrared, 2.09-2.35 $\mu \mathrm{m} ; \mathrm{G}=$ Band 5,

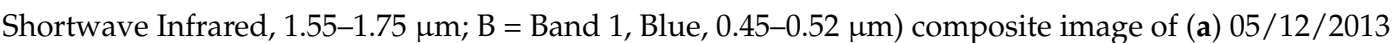
at 9.31 and (b) 24/12/2014 at $9.33 \mathrm{GMT}$; (c) change detection map showing the water affected areas, depicted in magenta, over the region of interest (ROI).

In Italy, the Ministry of the Environment and Land Protection plans finances and controls the actions aimed at the hydrogeological risk reduction. In this framework, the Hydro-Geologic Safety Plan (named hereafter PAI) is drawn up for each river basin. In the Basilicata PAI, produced by the Basilicata Inter-Regional Basin Authority, through hydrological and hydraulic studies carried out by the University of Basilicata [48], three areas of fluvial pertinence in relation to flood risk as well as in relation to the natural water path have been defined as areas of probable flood risk [48]. Such zones are established according to the three following scenarios: i) frequently occurring flood events (high probability, likely return period 30-50 years); ii) less frequently occurring flood events (medium probability, likely return period 100-200 years); iii) extreme flood events (low probability, likely return period 300-500 years). The last ones, delivered by the Italian national geoportal [43] and updated at December 2016, are provided in Web Map Service (WMS) format. The PAI referring to the ROI is shown in Figure 4, where the lighter the colour (from black to yellow) the lower the probability of the occurrence of extreme floods. 


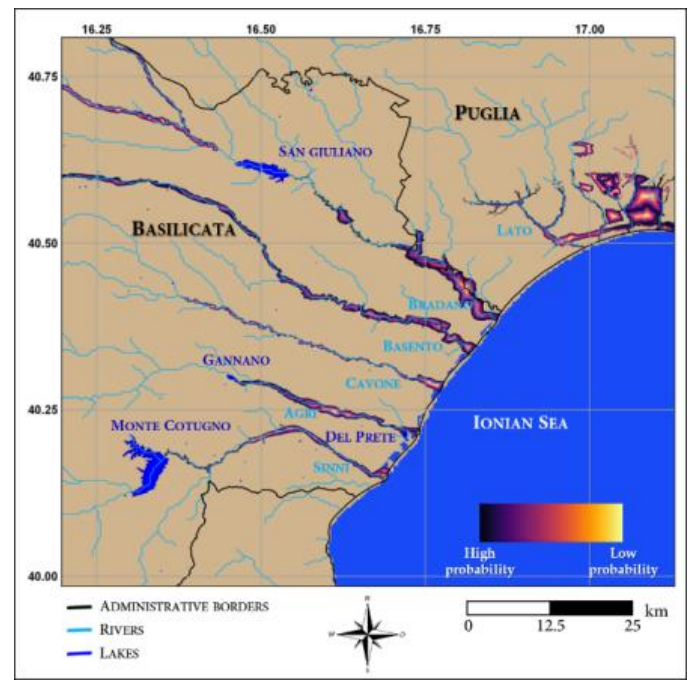

Figure 4. The flood hazard map (PAI) for the ROI. Areas are depicted according to the palette, ranging from black to yellow when the return period increases.

The VNG is a satellite-based flood extent product developed using SNPP/VIIRS imagery to derive near real-time flood maps for the National Weather Service (NWS) River Forecast Centres (RFC) in the USA [11]. It exploits a multi-step (decision trees) approach based on SNPP/VIIRS imagery to automatically generate near real-time flood maps in any land region between $80^{\circ} \mathrm{S}$ and 80 ${ }^{\circ} \mathrm{N}$ [11]. Geolocation (GITCO) and VIIRS data, such as the SNPP/VIIRS 750-m resolution cloud mask intermediate product (IICMO) and M-band terrain-corrected geolocation data (GMTCO) are also used in combination with several static ancillary datasets (e.g., global land cover, global land and water masks, digital elevation models, etc.). These data are integrated into the VNG software, using fixed threshold, contextual and change detection approaches to determine the presence of flooded areas, with a big effort toward the cloud and terrain shadow removal [11]. Since March 2018, the software has been delivered by CSPP in a version adapted for direct broadcast satellite receiving systems [44]. The software can process either full pass length SDRs by default or user defined latitude/longitude ROIs. The flood maps generated by VNG for the ROI shown in Figure 1 have been produced (Figure 5), considering the cloud-free VIIRS daytime imagery of the event. The output is a colour enhanced 8 bit GeoTIFF image with the main identified features differently depicted on the basis of the provided legend [44].

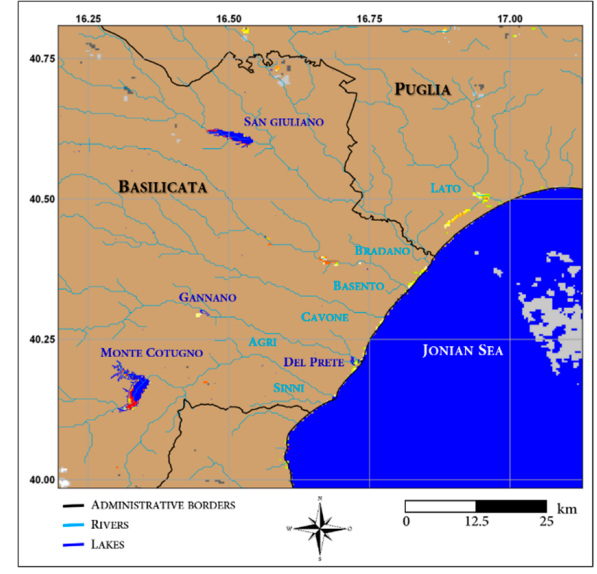

(a)

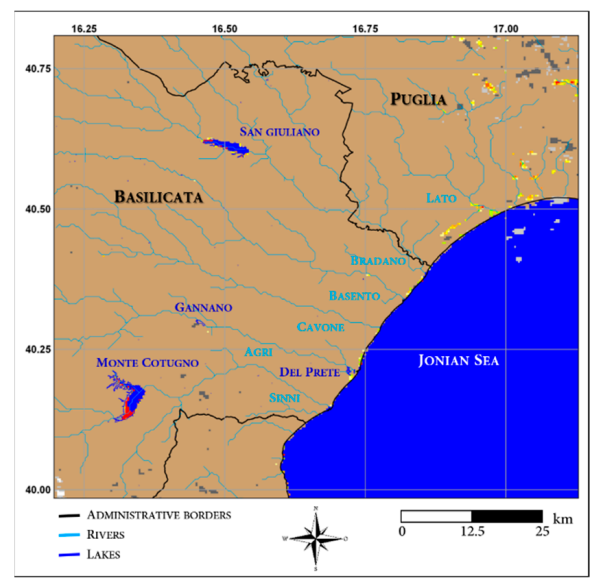

(b)

Figure 5. Cont. 


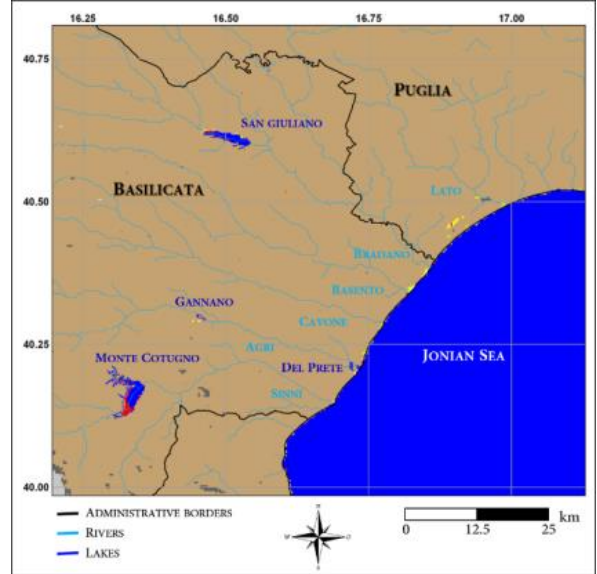

(c)

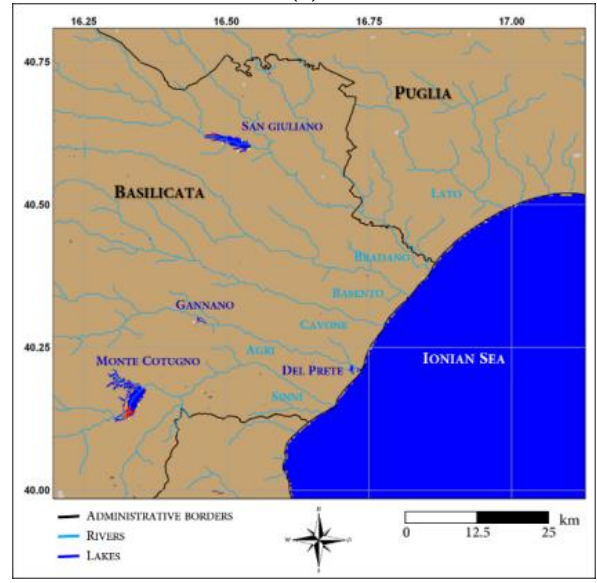

(e)

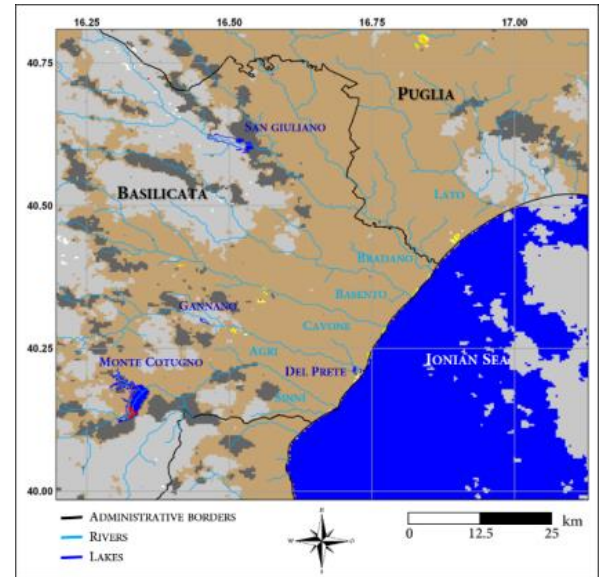

(d)

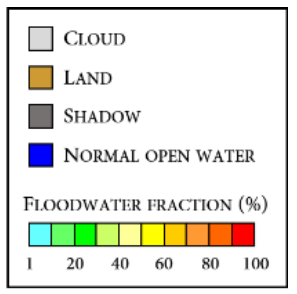

Figure 5. VNG products related to the ROI shown in Figure 1 for: (a) 04/12/2013 at 12:10 GMT; (b) 05/12/2013 at 11:52 GMT; (c) 06/12/2013 at 11:35 GMT; (d) 07/12/2013 at 11:12 GMT; (e) 08/12/2013 at $12: 36$ GMT.

\subsection{The Robust Satellite Techniques (RST) Approach}

RST is an automatic change-detection scheme, already applied with good accuracy in monitoring different natural and environmental hazards (see [21] and references herein). RST identifies statistically significant variations, at pixel level, for the signal under investigation by: (i) analysing multi-year time series of cloud-free homogeneous (same calendar month, same acquisition time, same spectral channel/s) satellite records; (ii) searching for anomalies by means of a specific change detection step. The latter exploits the "Absolute Variation of Local Change of Environment (ALICE) Index" defined as follows:

$$
\otimes_{V}(x, y, t)=\frac{\mathrm{V}(x, y, t)-\mu_{\mathrm{v}}(x, y)}{\sigma_{\mathrm{v}}(x, y)},
$$

where, $\mathrm{V}(x, y, t)$ is the signal measured at time $\mathrm{t}$ for each pixel $(x, y)$ of the analysed satellite scene, while $\mu_{\mathrm{V}}(x, y)$ and $\sigma_{\mathrm{V}}(x, y)$ represent respectively the temporal mean and standard deviation (i.e., the reference fields), both computed by processing the above mentioned homogeneous multi-temporal dataset of satellite imagery" [22]. Such an index is, for its inherent design, a standardized variable that should show a Gaussian behaviour (i.e., mean $\sim 0$ and standard deviation $\sim 1$ ), therefore, the higher the absolute value measured, the lower the probability of occurrence [49]. Namely, the probability of occurrence of an anomalous signal decreases from about $4.5 \%$ for $\left|\otimes_{\mathrm{V}}\right|>2$ (level of statistical significance) to $0.3 \%$ for $\left|\otimes_{\mathrm{V}}\right|>3$ and even lower values for increased $\left|\otimes_{\mathrm{V}}\right|$ [30]. The analysis at pixel level of long-term signal series acquired under the same observation conditions (i.e., same sun height, 
same land use/cover according to "seasonal" dynamics, almost similar weather/climatic conditions) automatically allows the overcoming of possible site effects [22]. For instance, any signal variation related to terrain shadows, which should be almost constant considering imagery acquired always in the same month of the year at the same time, is inherently taken into account by the proposed method. Furthermore, signal fluctuations due to spurious/random effects (sun glint contamination, suspended sediment variability, etc.) can only determine a higher standard deviation, thus resulting in a reduction of the ALICE index values and a much more selective identification of anomalous events [49,50]. As assessed by an independent work focused on RST [51], the investigated satellite historical series should consist of about 80 images to guarantee representative background signal. Such a number, considering a monthly temporal window and a sensor offering a daily temporal resolution, roughly corresponds to a 3-year long time series, representing indeed the minimum time span for a reliable RST implementation.

During the generation of the reference fields, as well as during the change detection step, cloudy pixels were identified and discarded from the detection step implementing the One Channel Algorithm (OCA) method [52,53]. Such an approach, still based on the RST prescriptions, analyses historical series of VIIRS I3 and I5 data to identify clouds as statistically high reflectivity or low temperature objects. Concerning cloud shadows, a specific algorithm based on ALICE indices (described in the next section) has been developed and tested here for the first time, to ensure a reliable identification of flooded area by optical data.

In its previous application to flooded area detection (e.g., [22,23]) RST-FLOOD used the ratio and/or the difference between the signals measured in the RED and NIR channels (i.e., RED/NIR and/or RED-NIR) of AVHRR (channel 1: 0.58-0.68 $\mu \mathrm{m}$ and channel 2: 0.725-1.00 $\mu \mathrm{m}$, both at $1 \mathrm{~km}$ of spatial resolution) and MODIS (channel 1: 0.62-0.67 $\mu \mathrm{m}$ and channel 2: 0.841-0.876 $\mu \mathrm{m}$, both a t $250 \mathrm{~m}$ of spatial resolution) as the reference signal (i.e., $\mathrm{V}(x, y, t)$ in Equation (1)). In particular, the ratio index demonstrated to be more robust respect to false positives, while the difference RED-NIR resulted more sensitive to the presence of flooded area [23].

Concerning VIIRS Imagery data, in addition to the indexes above defined [14], flooded area can be detected in different single bands and/or exploiting their combination, due to the specific spectral response of water in the VNIR region $[6,11,54]$. To better highlight such a behaviour within the local-scale conditions, the spectral profile for different signals along the red transect shown in Figure 1, has been investigated (Figure 6). Reflectance in both single (i.e., RED, NIR and SWIR, Figure 6a) and combined (i.e., RED - SWIR, RED/SWIR, NDSI-Normalized Difference Snow Index, Figure 6b) VIIRS I-bands were analysed.

Considering the reflectance trends along the selected transect at wavelengths between $0.6 \mu \mathrm{m}$ and $1.64 \mu \mathrm{m}$ (Figure 6a), a clear signal change is observable in correspondence of the areas perturbed by the water presence. In detail, the presence of turbid waters (i.e., rich in sediment) causes an I1 signal increase that is no more detectable in the two channels at higher wavelength, where the water absorption properties produce a signal decrease. The relative variation between probably flooded/no-flooded area is relatively higher for I3 channel (77\%) than I2 one (57\%), suggesting better sensitivity of I3 towards these features. According to these outcomes, within the band combination analysis (Figure 6b), we did not consider the NIR (I2) channel anymore. Plots shown in Figure 5b highlight the good sensitivity of the signal band combinations (i.e., I1-I3 or I1/I3) for flooded area detection, with the ratio providing the best score in terms of signal variation. In addition, also their combination in terms of normalized difference, namely the NDSI (NDSI = RED - SWIR/RED + SWIR [55]), proves to be an index suitable for water detection purposes [56] thanks to the high water reflectance contrast at these two wavelengths [11,15].

On the basis of the above discussed analysis, the ALICE index (Equation (1)) was preliminarily computed on the following five signals: I1, I3, I1 - I3, I1/I3 and NDSI = (I1 - I3/I1 + I3), in order to select the best suitable metric (single band or combination) for flooded area detection, in terms of both 


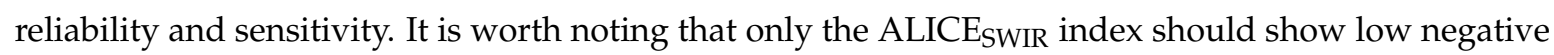
values in presence of flooded area, while, for all the others, high positive values have to be expected.

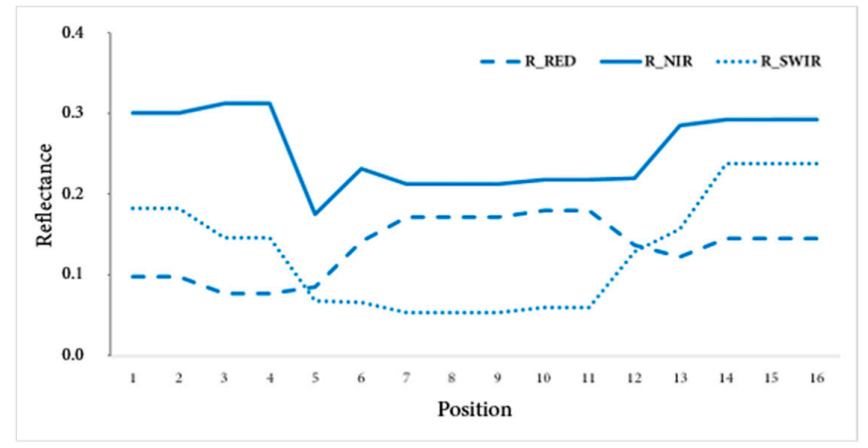

(a)

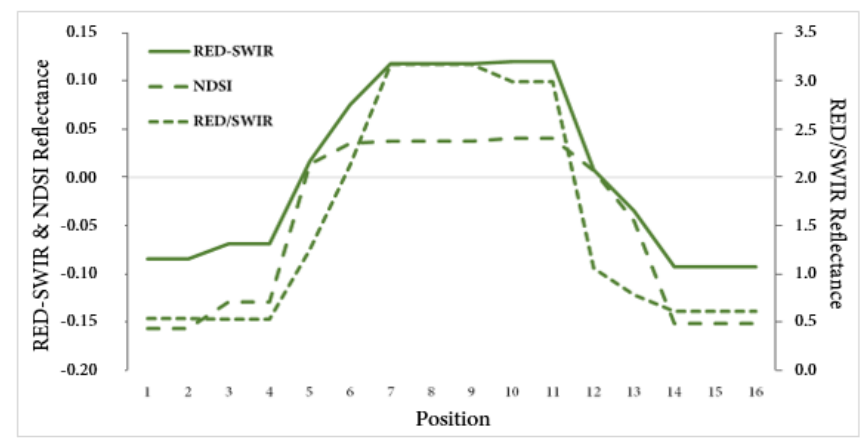

(b)

Figure 6. Reflectance variability profile along the red segment shown in Figure 1 for: (a) RED (I1), NIR (I2), SWIR (I3) VIIRS I-bands of 04/12/2013 at 12.10 GMT and the combinations (b) RED - SWIR, RED $/$ SWIR, NDSI $=($ RED - SWIR $) /($ RED + SWIR $)$.

\subsection{Cloud Shadows Removal}

In this study, we investigated, for the first time, the potential of the RST approach to identifying cloud shadows, using the VIIRS I-bands. It is worth pointing out that, to our knowledge, this is the first attempt to exploit these data to detect cloud shadows. The current cloud mask algorithm for VIIRS I-Band indeed does not contain any confidence flag for shadows [57]. It is also important to specify that the approach we are proposing is based on a preliminary version, implemented for identifying (and removing before further analyses) clouds shadows (just for clouds on land). The performances it offers using the developed criterion, shown in this paper, refers exclusively to the flood analysed in this work. Other tests on wider regions are needed to confirm its feasibility and make it working well for all situations. In this first approach, the algorithm does not use geometry-based information (e.g., view angle of the satellite sensor, the solar zenith angle, the solar azimuth angle and the relative height of the cloud) to assess the cloud shadow location. In any case, it is worth mentioning that an assessment of the reliability of the RST-based cloud shadow product is beyond the scope of this paper and will be object of future works.

Cloud shadows can be considered, from a statistical point of view, as anomalous signals randomly perturbing the investigated signal at pixel level for the considered scene. Therefore, they can be analysed by implementing the RST approach selecting spectral radiances most sensitive to their presence [58], namely the reflectance values measured in the I1, I2 and I3 VIIRS bands. [58] showed the difference of reflectance values between clear pixels and cloud shadow contaminated pixels on vegetation, settlement and water bodies are shown, for the Landsat 8 bands (from Blue to SWIR). They found that NIR and SWIR bands have the biggest difference in average between clear pixels and cloud 
shadow contaminated pixels. Despite this, the choice of the most suitable metric (e.g. between the single or a bands combination) is not trivial, as shadows show a spectral response in the VIS-SWIR spectral range almost similar to those of flooded area [59]. Investigating the differences in values of the ALICE indices (i.e., ALICE $_{\text {RED }}$, ALICE $E_{N I R}$ and ALICE $_{S W I R}$ ) for shadows and flooded area, it is worth considering that:

- in the RED (I1), flooded pixels should show higher values of ALICE $E_{R E D}$ than the shadow-affected ones, due to their relative increase in reflectance at this wavelength;

- in the NIR (I2) and SWIR (I3), both flooded and shadow pixels show low (negative) values of ALICE $_{\text {NIR }}$ and ALICESWIR.

Therefore, a combination of those signals can allow a quite reliable identification of cloud shadows, which were mapped using the following rule:

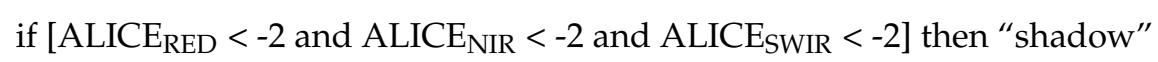

where the value "-2" used for all ALICE indices is the minimum level assuring the statistical significance of detected pixels. Besides, a $1.5 \mathrm{~km}$ - buffer zone around each potential cloud shadow affected pixel has been applied, to compensate for missed detections.

For its inherent construction, such a criterion, applied only on cloud-free pixels, looks for those areas concurrently showing a statistically significant decrease in the signal acquired in the first three VIIRS Imagery bands. Therefore, apart from a few spurious and random signals, it should allow at discriminating flooded area from cloud shadows.

\section{Results}

\subsection{Cloud Shadow}

The cloud and shadow masks produced by the approach above mentioned are shown in Figure 7 and refer to the most two cloudy (on land) images (i.e., 05/12/2013 at 11:52 GMT and 07/12/2013 at 11:12 GMT, see Figure $5 b, d$ ) among the ones analysed in this paper. Furthermore, for each of them, also the corresponding VIIRS RGB false colour image is plotted.

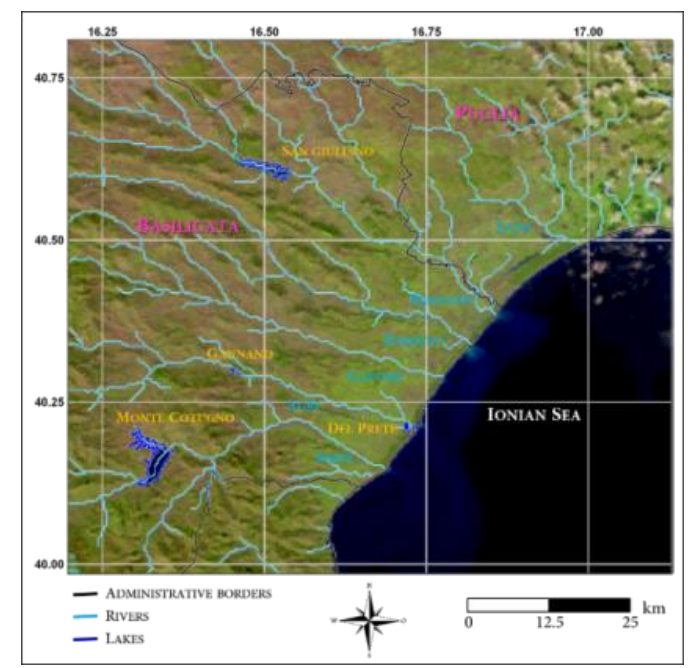

(a)

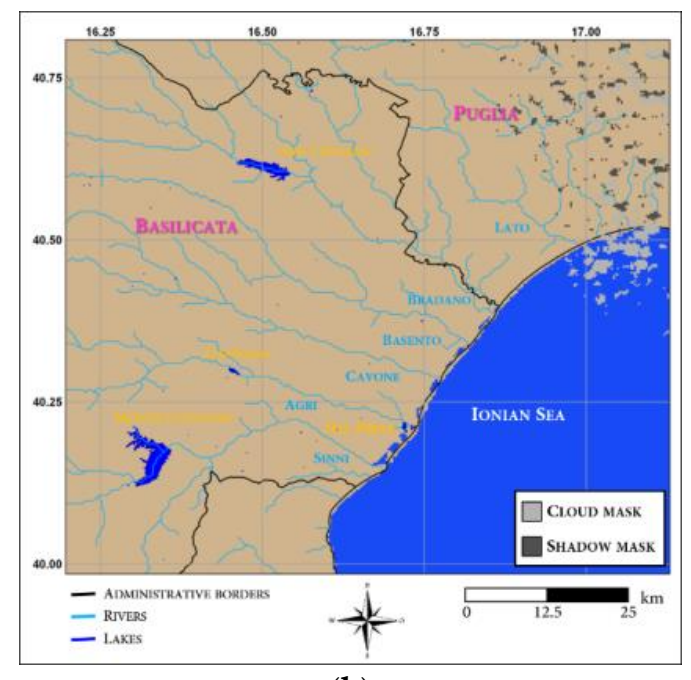

(b)

Figure 7. Cont. 


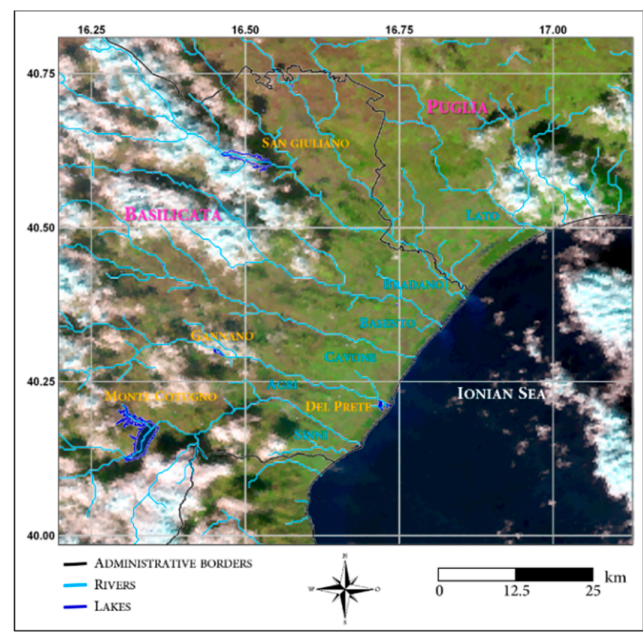

(c)

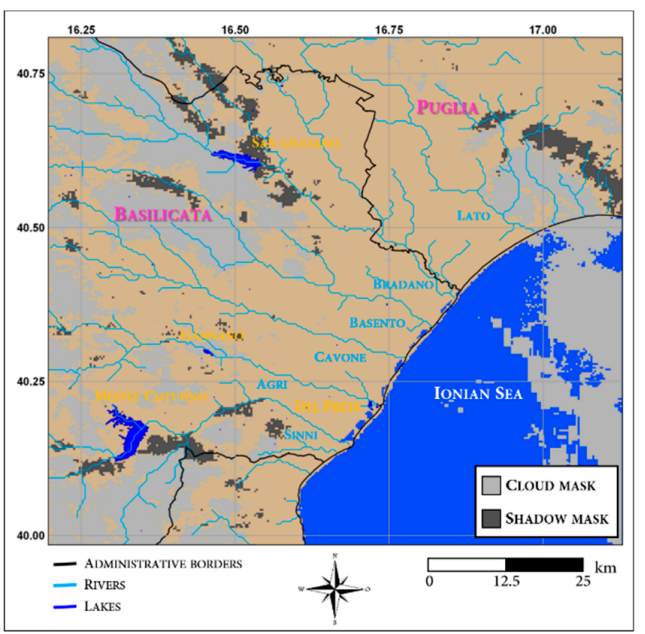

(d)

Figure 7. (a) RGB False Colour ( $R=$ SWIR, $G=N I R, B=R E D)$ of VIIRS Imagery data acquired on 5 December 2013 at 11:52 GMT; (b) cloud and shadow masks for the image shown in (a); (c) RGB False Colour ( $\mathrm{R}=$ SWIR, G = NIR, B = RED of VIIRS Imagery data acquired on 7 December 2013 at 11:12 GMT; (d) cloud and shadow masks for the image shown in (c).

The maps in Figure $7 \mathrm{~b}$,d seem to indicate the good potential of this preliminary RST-based indicator in detecting anomalous pixels likely affected by cloud shadows. The visual comparison to the VNG outputs (see Figure $5 b, d$ ) also indicates a general agreement between the two products, even if a straight inter-comparison is not possible, because of the different cloud detection strategy adopted. Obviously, at the current state, residual cloud shadows not properly identified will expose RST-FLOOD to possible false positive detection.

\subsection{Selection of the Most Suitable VIIRS RST-FLOOD Indicator}

As already mentioned, the first almost cloudy-free VIIRS daytime image acquired over the area under investigation soon after the event was on 4 December 2013 at 12:10 GMT, shown in RGB False Colour ( $\mathrm{R}=\mathrm{I} 3, \mathrm{G}=\mathrm{I} 2, \mathrm{~B}=\mathrm{I} 1)$ in Figure 1. This image has been selected as benchmark for assessing ALICE indices performances (Figure 8), being the one temporally closest to the flood peak. In each of the five maps reported in Figure 8, pixels showing statistically significant (i.e., higher/lower than $|3|$ ) ALICE values have been depicted in red.

The results based on the ALICE $E_{\text {RED }}$ index (Figure 8a) highlighted its poor reliability in discriminating flooded pixels. Although several pixels are located along the main rivers in the area, there are indeed more others randomly spread out all over the ROI. These effects disappear in all the other maps, whose analysis seems to suggest a quite similar behaviour for the other four indices.

Hence, excluding the ALICE $E_{\text {RED }}$ index (Figure 8a), the number of flooded pixels identified all over the scene by each of the other indices has been summarized in Table 2, in which also the mean and maximum ALICE values are reported. The same information has been listed for anomalous pixels detected along the Basento River.

The ALICE $E_{S W I R}$ appears as the most conservative index in identifying anomalous pixels, compared with the others (see Table 2). An in-depth investigation of anomalies discriminated by all the other indices suggests the following considerations. The ALICE index, when using the RED and SWIR reflectances, combined as difference, ratio and normalized difference, overall provide the same information on flooded area extent, flagging as anomalous a very similar number of pixels (see Table 2). In particular, among them, the ALICE $E_{\text {RED-SWIR }}$ and ALICE $_{\text {RED/SWIR, unlike the ALICE }}$ NDSI, seem more exposed to the detection of anomalous/spurious pixels along the coastline. Accordingly, the ALICE $_{\text {NDSI }}$ appears as the most performing index, offering the best trade-off between sensitivity and reliability. 


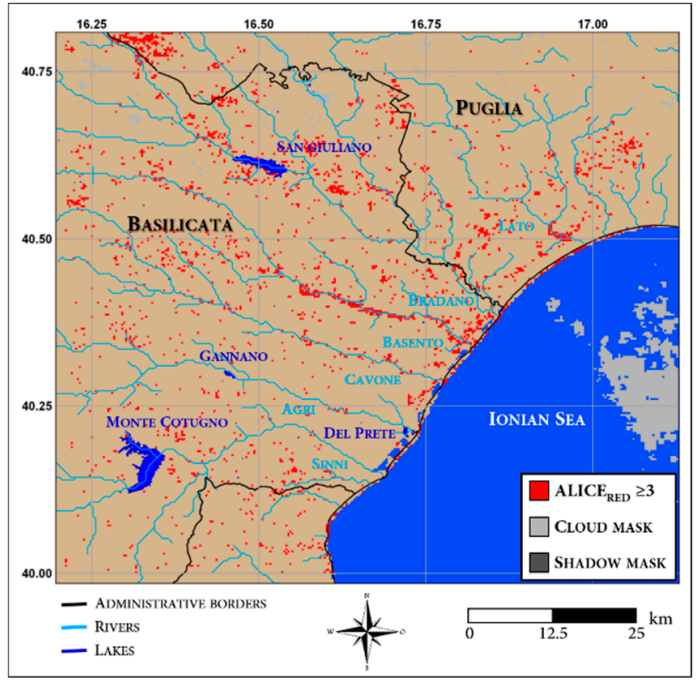

(a)

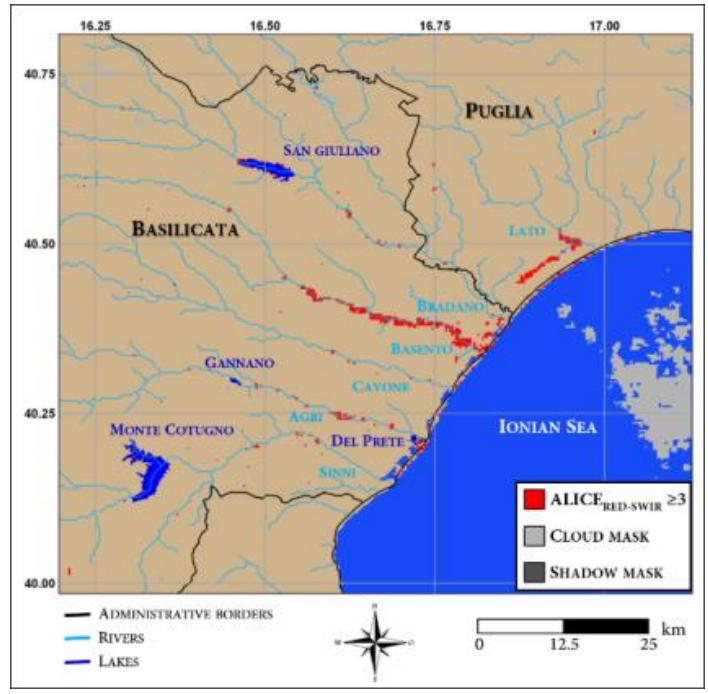

(c)

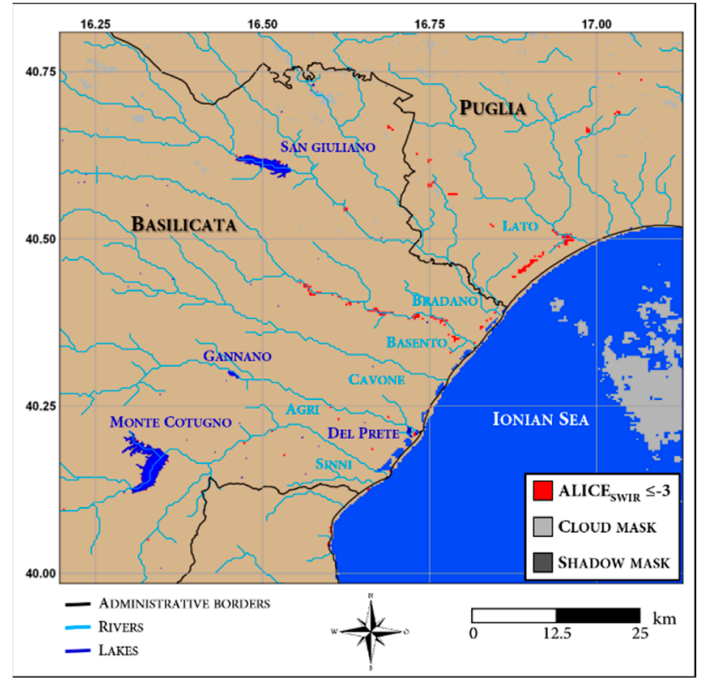

(b)

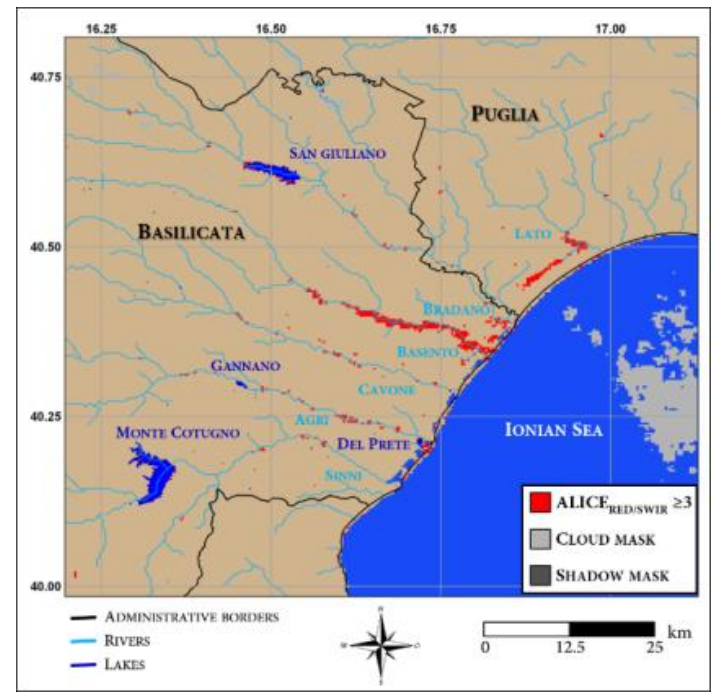

(d)

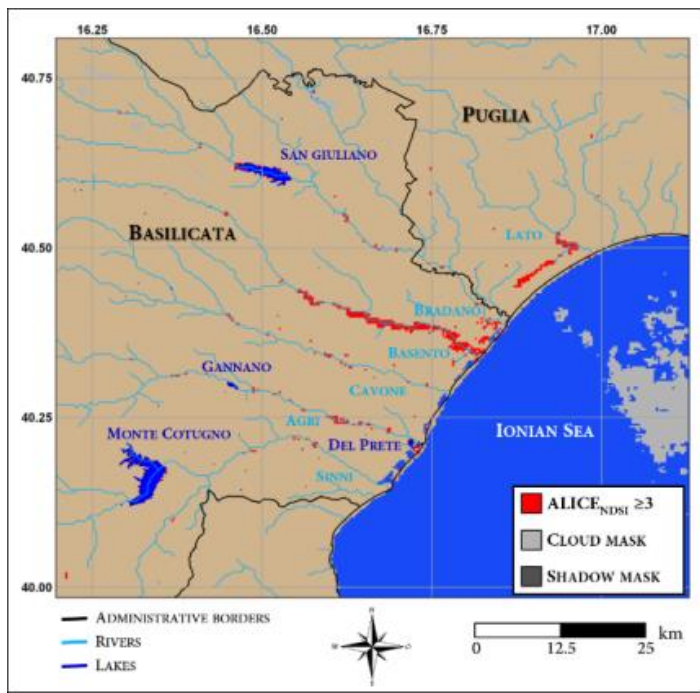

(e)

Figure 8. Anomalous pixels detected by: (a) ALICE $_{\text {RED, }}$ (b) ALICE $_{\text {SWIR, (c) }}$ ALICE $_{\text {RED-SWIR, }}$ (d) ALICE $_{\text {RED-SWIR, }}$ (e) ALICE $_{\text {NDSI }}$ on 04/12/2013 at 12:10 GMT. 
Table 2. Statistics of the ALICE indices all over the scene and for anomalous pixels along Basento River.

\begin{tabular}{ccccccc}
\hline \multirow{2}{*}{$\begin{array}{c}\text { ALICE } \\
\text { Index }\end{array}$} & \multicolumn{3}{c}{ All Scene } & \multicolumn{3}{c}{ Basento River } \\
\cline { 2 - 7 } & \# Anomalous Pixels & Mean & Max/Min & \# Anomalous Pixels & Mean & Max/Min \\
\hline ALICE $_{S W I R}$ & 220 & -2.42 & -28.16 & 71 & -3.98 & -7.48 \\
ALICE $_{\text {RED-SWIR }}$ & 604 & 4.70 & 17.15 & 230 & 6.28 & 17.15 \\
ALICE $_{\text {RED/SWIR }}$ & 679 & 8.92 & 61.83 & 247 & 3.06 & 61.83 \\
ALICE $_{\text {NDSI }}$ & 638 & 5.78 & 23.74 & 256 & 3.01 & 23.74 \\
\hline
\end{tabular}

The analysis for the Basento River shows almost similar outcomes respect to the whole scene in terms of detected ALICE values but with the ALICE $_{\text {NDSI }}$ identifying the largest number of anomalous pixels (i.e., 256). Therefore, on the basis of the above discussed results, the ALICE $\mathrm{NDSI}_{\text {I }}$ has been selected as the benchmark index in the next analyses, resulting less affected by suspended sediments and showing a good sensitivity in detecting flooded area.

A map of the detected anomalous areas for the VIIRS image of 4 December 2013 is plotted in Figure 9 where different colours (from red to yellow) indicate increasing significance levels of the

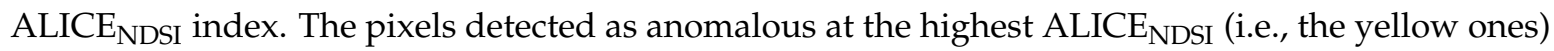
are representative of local conditions extremely different from those expected in the ROI.

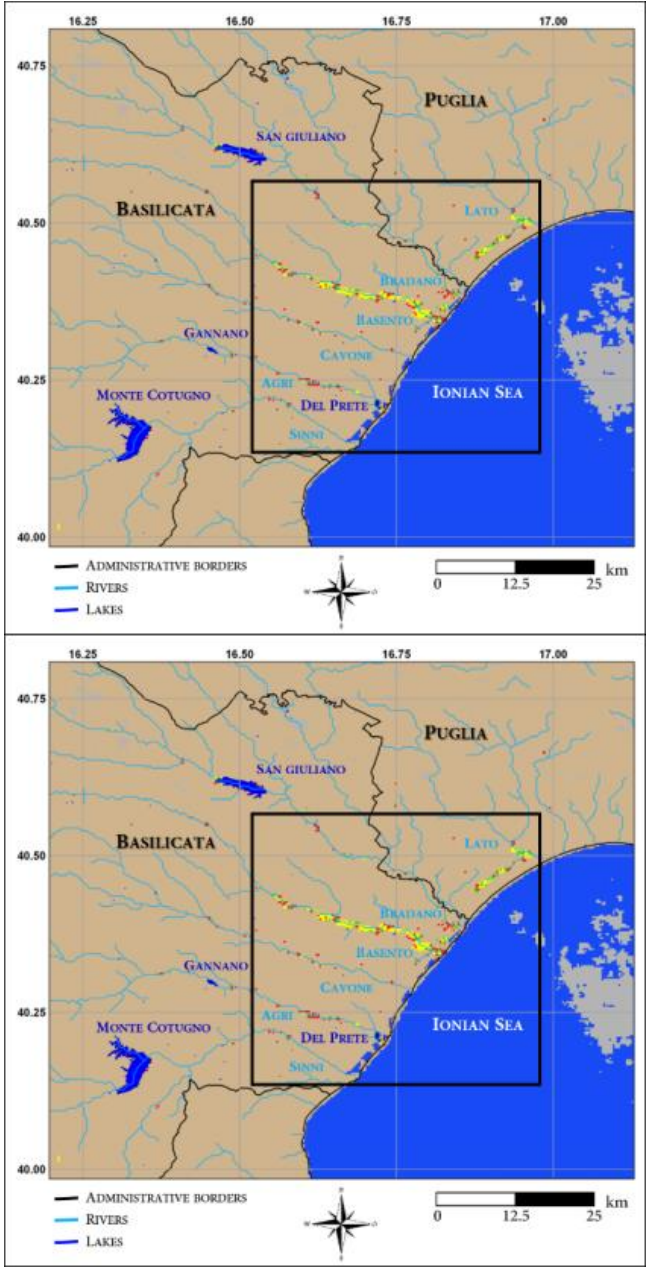

(a)

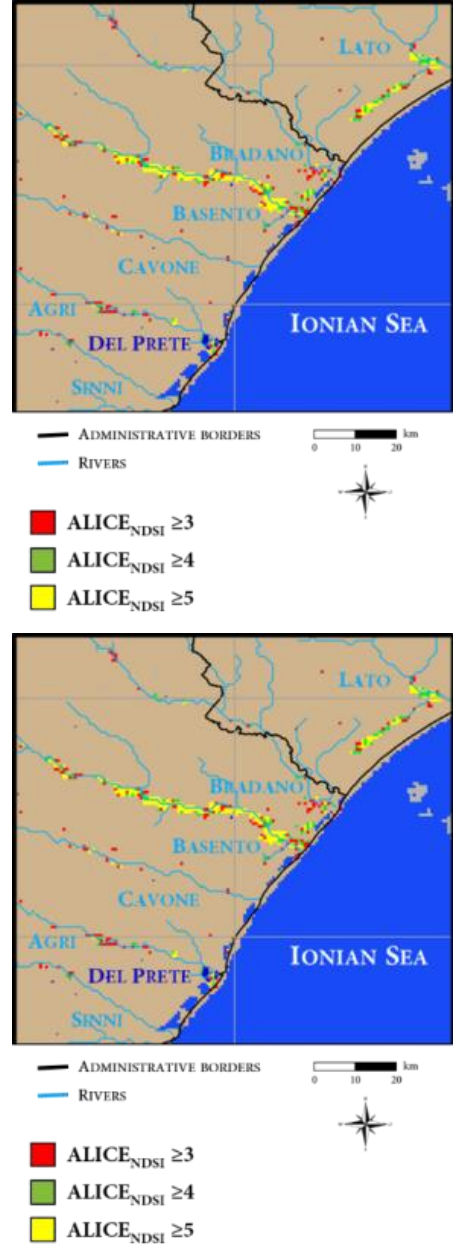

(b)

Figure 9. (a) Flooded areas detected within the ROI by ALICE $E_{\text {NDSI }}$ on 04/12/2013 at 12:10 GMT at increasing levels of the confidence from red to yellow; (b) magnification of the area within the white box shown in Figure 1. 
Once the most suitable ALICE index has been defined, it has been applied also on the next four days (i.e., up to 8 December 2013), when the event should have been already ended, according to previous works (e.g., [31,37]).

The map including all the anomalous pixels detected by the ALICE $_{N D S I} \geq 3$ during the five days is reported in Figure 10, clearly showing as the probably effects of the event were still evident up to 8 December at least. In the following days, the ROI was again cloudy up to 10 December 2013, when the flood effects were almost disappeared. The spatial extent of the detected anomalies during the five-day period was about $72 \mathrm{~km}^{2}$ on December 4 th, $41 \mathrm{~km}^{2}$ on 5 th, $32 \mathrm{~km}^{2}$ on 6 th, $38 \mathrm{~km}^{2}$ on 7 th and $30 \mathrm{~km}^{2}$ on 8 th December 2013, respectively. A clear decreasing trend in the anomalous area identification is notable (as expected in the case of floods), except for 7th December, when the large presence of clouds and relatively shadows may have produced a few false positives (see green pixels in Figure 10). Moreover, the clusters of anomalous pixels in correspondence of the main affected rivers as well as their persistence in the spatiotemporal domain, suggest their possible direct correlation with the flooded area that will be assessed in the next session.

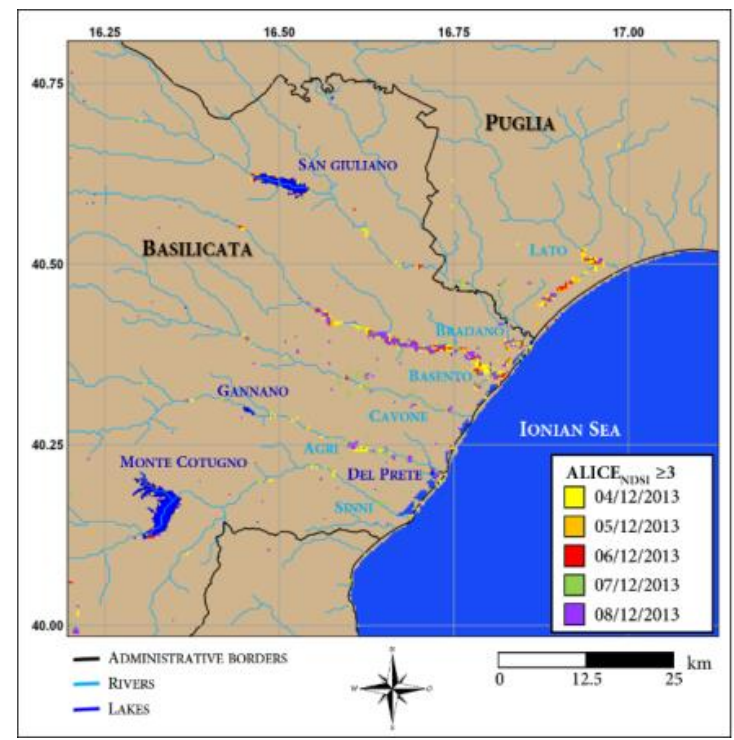

Figure 10. Flooded areas detected within the ROI by $\mathrm{ALICE}_{\mathrm{NDSI}} \geq 3$ on days between $4-8$ December 2013.

\subsection{Assessment Results}

\subsubsection{Comparison with Landsat 7 ETM+ Data}

The RST-FLOOD results referring to 5 December 2013 were superimposed on the water affected areas shown in Figure $3 \mathrm{c}$ in order to assess their reliability. By comparing the areas detected as flooded by RST-FLOOD (orange pixels in Figure 10) and the change detection scheme, described in Section 3.2, on Landsat 7 ETM+ data (Figure 3c), a very good level of agreement can be observed (Figure 11).

Across the scene, 191 and 357 pixels were flagged as flooded in the Landsat and RST-FLOOD map, respectively, with 120 common detections (Figure 11a). The remaining Landsat water affected pixels, not detected by RST-FLOOD, are around the lakes/dams (35\%) and along Basento and Bradano rivers (65\%). Within the box (Figure $11 \mathrm{~b}$ ), $\sim 90 \%$ of total pixels detected by Landsat (i.e., 104) are also identified by RST-FLOOD that found a total of 293 pixels. Those remaining are all along the Basento and Agri rivers and were not detected by Landsat due the already-mentioned data gap acquisition. 


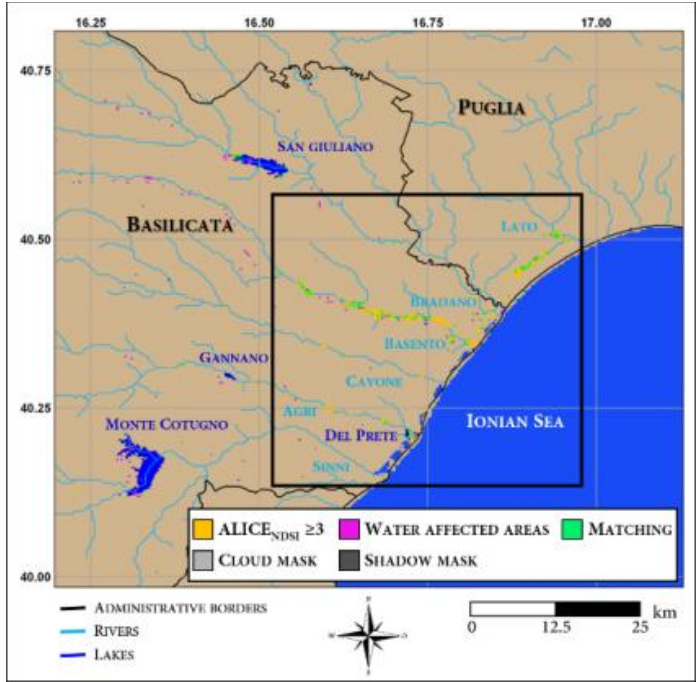

(a)

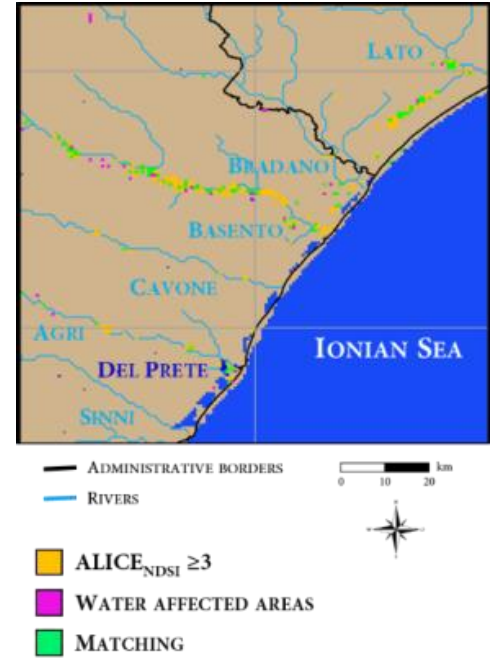

(b)

Figure 11. (a) Comparison between the flooded affected areas detected by RST-FLOOD for the 5 December 2013 (orange pixels) and the water affected areas computed by a change detection scheme on Landsat data (magenta pixels); the common pixels are highlighted in green; (b) a magnified map of (a) within the white box shown in Figure 1.

\subsubsection{Comparison with the Flood Risk Map}

The flood hazard map (Figure 4) provided by the Italian Ministry of the Environment and Land

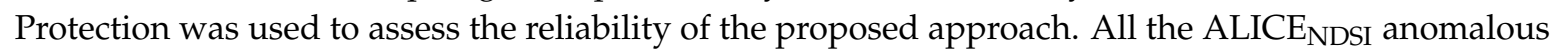
pixels detected by RST-FLOOD in the 4-8 December 2013 temporal range have been superimposed on the PAI area (Figure 12).

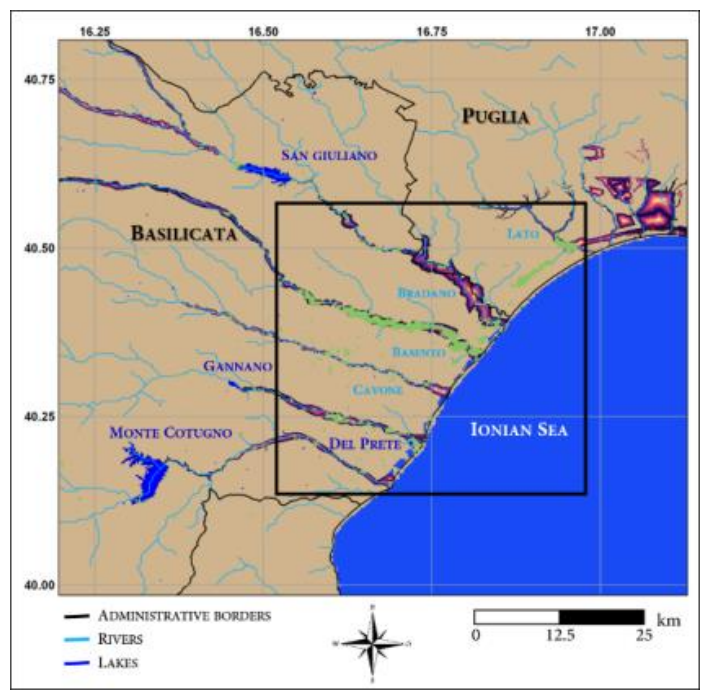

(a)

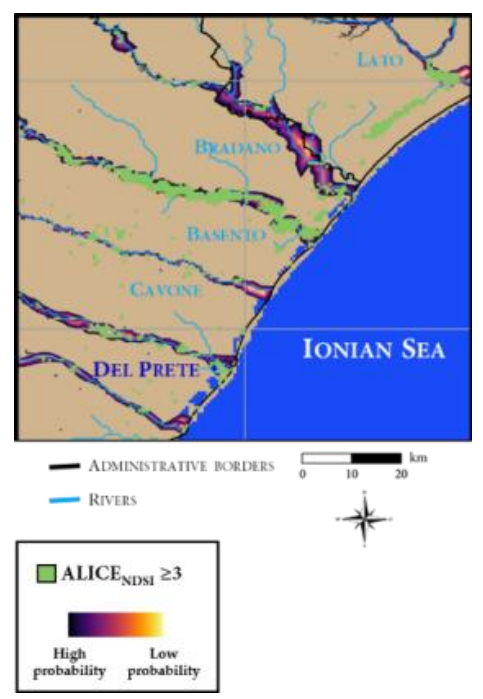

(b)

Figure 12. (a) PAI and anomalous pixels detected by RST-FLOOD (ALICE $E_{\text {NDSI }} \geq 3$ ) in 4-8 December 2013 over the ROI; (b) a magnified map of (a) within the white box shown in Figure 1.

Table 3 summarizes the amount of anomalous pixels falling or not within the PAI area, counted considering both the whole scene and the above-mentioned black box (shown in Figure 12b). 
Table 3. Number of anomalous ALICE $E_{\text {NDSI }}$ pixels detected in the 4-8 December 2013 period, included or not within the PAI area all over the scene and only for the white box (Figure 12b).

\begin{tabular}{ccccc}
\hline & \multicolumn{2}{c}{ All scene } & \multicolumn{2}{c}{ Black Box } \\
\cline { 2 - 5 } & Pixels Number & $\%$ & Pixels Number & $\%$ \\
\hline included in PAI area & 617 & $68 \%$ & 537 & $76 \%$ \\
not included in PAI area & 295 & $32 \%$ & 172 & $24 \%$ \\
\hline
\end{tabular}

The analysis of the results reveals that $68 \%$ of detected pixels within the whole ROI were in agreement with the PAI area. In addition, looking at Figure 12a, only a very low number of pixels seem to not be directly correlated with the hydrographic network of the ROI, indicating a general good reliability of the achieved results. In more detail, among the $32 \%$ of detections outside PAI area (equal to 295 pixels), i) $20 \%$ (i.e., 60 pixels) is related with the area/border of the two already cited dams, ii) $36 \%$ (i.e., 105 pixels) takes into account of pixels close to the coastline as well as to the rivers but outside the above mentioned zone and hence likely to be considered false positives, iii) the most of the remaining $44 \%$ (i.e., 130 pixels) of pixels is clustered in two sub-areas, clearly visible in Figure 12b, one is located between the mouth of the Bradano and Basento rivers and the other is on the left side of the Lato River. The first one was already identified as inundated by Reference [31] and [37], the latter, here identified for the first time, refers to the Castellaneta Marina village, where the freeway "StradaStatale 106 " was closed due to the large presence of water [32-36]. Furthermore, it is worth mentioning that these two areas with an estimated extension of about $18.3 \mathrm{~km}^{2}$, are not contemplated in the current flood risk map, suggesting a potential of satellite-based products even in terms of assessing (and possibly refining) such administrative instruments.

The performance of the results improves when considering only the area within the black box, namely that mainly affected by the event. In particular, among the 172 pixels not included in the PAI area, 31 (i.e., 18\%) are probably due to spurious effects, while the remaining 141 pixels (i.e., $82 \%$ ) correspond to above-mentioned "flooded for sure" areas. Finally, $96 \%$ of the detected anomalies within the black box can be considered as real flooded area. This number decreases (i.e., $82 \%$ ) accounting for the whole ROI, even if $36 \%$, of the remaining $18 \%$, is related with the borders of the San Giuliano and Monte Cotugno dams. Therefore, in absence of other information/documentation about other inundated zones within the ROI, only a residual possible $18 \%$ of false positives has been estimated,

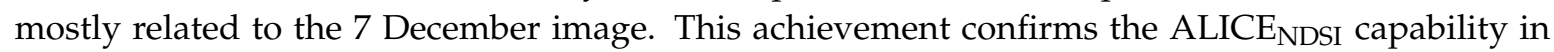
flooded area detection with a high level of reliability.

\subsubsection{Comparison with VNG}

The VNG maps generated for the analysed VIIRS data are plotted in Figure 5, where pixels with an increasing percentage of floodwater fractions are depicted from cyan to red. In these maps it is possible to identify different and quite persistent flooded area, mostly located along the Basento and Lato rivers as well as at the border of the Monte Cotugno and San Giuliano dams. Finally, the north-eastern sector of Figure $5 \mathrm{a}, \mathrm{b}, \mathrm{d}$ is characterized by some possible false positives, probably related to cloud shadows.

All these features are also evident in Figure 13, where flooded pixels, detected by means the

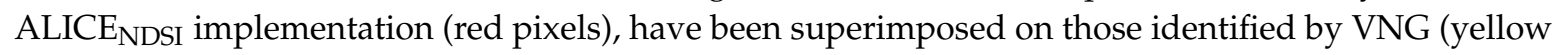
pixels), regardless their confidence level. Pixels commonly identified as flooded by both the algorithms have been depicted in green.

The two products generally show a good agreement, considering that both the algorithms are able to detect the main spatial features along the Basento and Lato rivers as well as the areas bordering the Monte Cotugno and San Giuliano dams. Even taking into account a different sensitivity in the identification of probably flooded pixels, residual biases are due to effects related to the different land-sea mask used as well as to the already mentioned cloud shadows issues. Table 4 summarizes the 
number of probably flooded pixels detected by RST-FLOOD and VNG considering both the whole scene as well as the black box for the five analysed days, exploring also common detections.

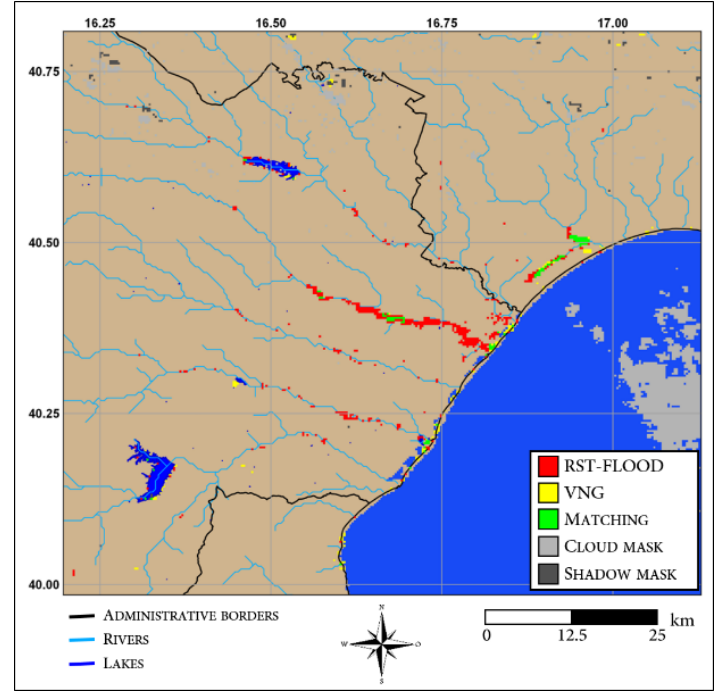

(a)

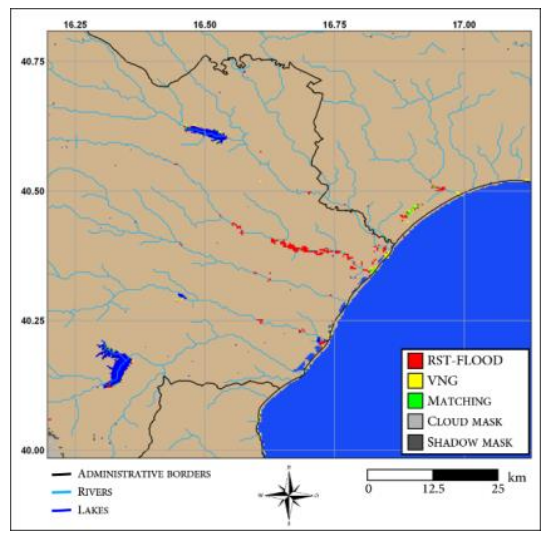

(c)

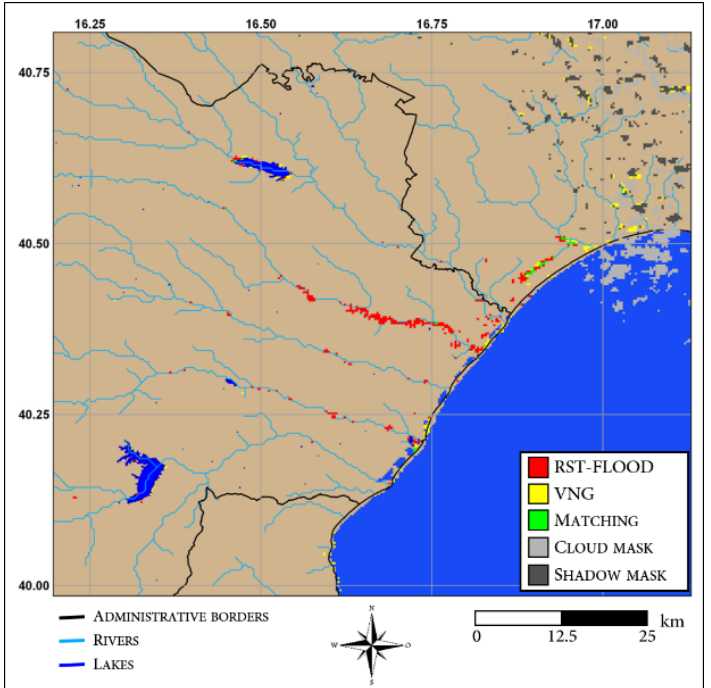

(b)

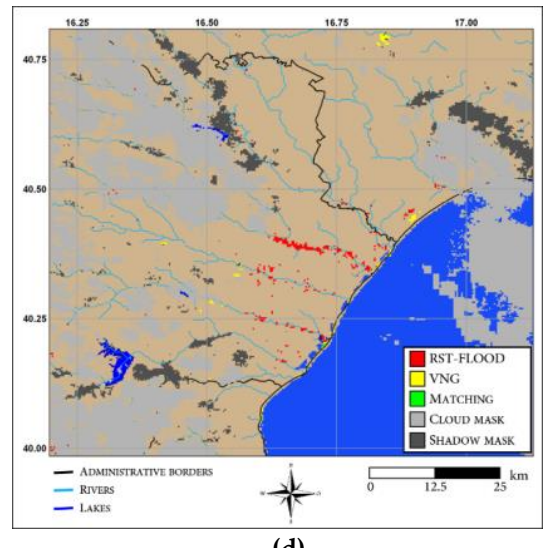

(d)

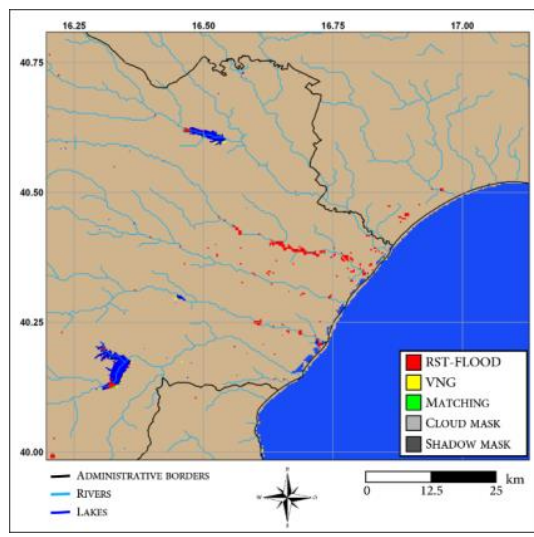

Figure 13. Comparison between flooded areas detected by RST-FLOOD using ALICE $\mathrm{NDSI}_{2} \geq 3$ (red pixels) and VNG (yellow pixels) on VIIRS data acquired on: (a) 04/12/2013; (b) 05/12/2013; (c) 06/12/2013; (d) 07/12/2013; (e) 08/12/2013. Common detections are depicted in green. 
Table 4. Number of pixels detected by RST-FLOOD, VNG and by both the algorithms (as shown in Figure 13) for the analysed days.

\begin{tabular}{ccccccc}
\hline & \multicolumn{3}{c}{ All Scene Pixels Number } & \multicolumn{3}{c}{ Black Box Pixels Number } \\
\hline VIIRS Data & RST-FLOOD & VNG & MATCHING & RST-FLOOD & VNG & MATCHING \\
\hline $04 / 12 / 2013$ & 638 & 454 & 109 & 510 & 184 & 96 \\
$05 / 12 / 2013$ & 357 & 481 & 36 & 293 & 111 & 31 \\
$06 / 12 / 2013$ & 267 & 234 & 26 & 226 & 84 & 18 \\
$07 / 12 / 2013$ & 345 & 196 & 4 & 317 & 71 & 4 \\
$08 / 12 / 2013$ & 260 & 137 & 3 & 211 & 10 & 0 \\
\hline
\end{tabular}

VNG seems to detect fewer anomalous pixels than RST-FLOOD, especially along the Basento River, as is clearly observable in Figure 13. This effect is more evident considering the detection statistics related to the black box, where the area most affected by the event is included. The comparison between VNG results and those achieved by the change detection scheme on Landsat data, as already done for RST in Section 4.3.1, returns a $26 \%$ of common detections (i.e., 49 pixels) on the whole scene and a $47 \%$ in the black box. Starting from the 6 December 2013 (Figure 13c) map, any flooded area around the Basento River has been detected by VNG, whose identifications are mainly focused on Lato River. It is worth noting that, to reduce the false detection [11], the minor flood detection within VNG is only done around the determined floodwater pixels or existing normal water pixels (rivers, lakes or reservoirs) and therefore a water mask not perfectly updated could be at the basis of these discrepancies.

\section{Discussion}

Floods are natural disasters that, due to their clear spatial and spectral markers in different regions of the electromagnetic spectrum, are more easily investigable by means of satellite data [14]. Among the different satellite-based contributions useful for the flood risk management cycle, is the generation of reliable multi-temporal flood maps is fundamental in all the different phases [8,60,61]. Optical sensors onboard polar satellites can assure the better trade-off among spectral/spatial/temporal resolutions suitable for a near real time and continuous monitoring of flooded area [62] although cloud coverage can fully or partially hamper the acquisition of useful data in this spectral region, possibly limiting their applicability [7]. Among the currently operational optical sensors, VIIRS onboard SNPP is one of the most recent and advanced, assuring a long-term continuity of observation (up to the 2031, [38,39]), that is crucial to assess its potential in investigating floods as well as other natural disasters $[40,54]$.

In this work, the RST-FLOOD approach, previously applied to AVHRR and MODIS VNIR data, has been fully implemented for the first time on historical series of VIIRS Imagery records for evaluating its capability in detecting inundated area. The adoption of dynamic and local-scale self-adaptive thresholds and the fully independence on any kind of auxiliary/ancillary information are the main RST-FLOOD advantages with respect to traditional techniques [14,23]. Fixed thresholding schemes or ancillary dataset are indeed often used for flooded area detection applications $[11,54]$ as well as for facing issues related to cloud and terrain shadows, representing the main challenges for a fully reliable flood detection $[11,54]$. The results performance of inundated area identification can indeed largely change depending both on the availability and the accuracy of the used auxiliary/ancillary information [22]. In addition, specific site/local-setting of the investigated scene, as well as seasonal/ meteorological variations of the studied signals, may negatively affect the sensitivity of fixed thresholds schemes $[14,22]$.

Focusing on the RST-FLOOD-based application shown in this paper, the flood event that affected the Basilicata and Puglia regions in the first week of December 2013 has been investigated, producing satisfactory results, which further confirm the great potential of the proposed approach in detecting flooded areas.

Flood evolution in the spatiotemporal domain has been accurately identified, well over the spatial extent and temporal interval suggested by other works [31,37]. A total area of about $73 \mathrm{~km}^{2}$ was 
identified as inundated during the investigated period, with a good level of reliability, as highlighted by the validation analysis performed through the comparison with the PAI map. About $68 \%$ of the detected anomalies falls within the PAI, $6.5 \%$ refers to the borders of the San Giuliano and Monte Cotugno dams, $11.5 \%$ takes into account pixels close to the coastlines and rivers but outside the above mentioned zone, representing possible false positives. The remaining $14 \%$ represents a "for sure" flooded area located in correspondence of the Castellaneta Marina town and between the Bradano and Basento mouths. This last finding is particularly significant because it highlights an area that, although clearly flooded in 2013, has not yet included in the current flood hazard map, revealing the added value that robust satellite algorithms may provide in improving flood risk management.

Comparison with the results provided by implementing another VIIRS-based method [11] seems to confirm the good capability of RST-FLOOD to detect inundated area. Although some differences are inherently due to the different approach at the basis of the two algorithms, some others are attributable to the assumption that VNG has been developed to work at global scale (between $80^{\circ} \mathrm{S}$ and $80^{\circ} \mathrm{N}$ ) and set more towards reliability than sensitivity. Moreover, a few of the static ancillary databases used within this software might not be updated respect to the local conditions faced in this work.

Despite these satisfactory achievements, a few possible sources of inaccuracies (i.e., the above cited $11.5 \%$ of possible false positives) have been identified and are briefly discussed as follows.

Cloud shadows, representing the main issue limiting flood detection reliability, can be considered as random and spurious signals perturbing the reflectance field measured in the VIS-SWIR spectral region. Therefore, in this paper, their identification has been addressed developing an original RST-based approach exploiting VIIRS I1, I2 and I3 bands reflectance (see Section 3.4). In detail, the combination of the signal acquired in these three bands has been used to discriminate cloud shadows from flooded area and other features. Preliminarily results here presented seem to confirm the feasibility of this approach, even if, a few omission errors have been identified, producing false positive detections. Further analyses aimed at assessing the accuracy of these achievements will be performed in the future, in order to better investigate if other possible signal combinations may provide any improvement.

Residual geo-location errors or the use of a land-sea mask not perfectly co-located with the analysed data may produce a few false positive along coastlines. In these zones, the concurrent presence of water and land produces a mixed spectral signature at pixel level that is generally taken into account by standard deviation in the RST-FLOOD approach. When a seawater-like signal is compared with a land-like one a few errors may be detected, thus suggesting a check on the geo-location data accuracy.

The inflow of anomalous concentration of suspended sediments from lakes (dams) within the ROI has affected the signal measured by VIIRS especially at low wavelengths (i.e., I1 band) especially on the RED and SWIR bands combination (i.e., Ratio and Difference), also in terms of ALICE index implementation (see Section 4.1). Within the RST framework, this is an expected and obvious result because it highlights the occurrence of conditions extremely different from the expected one, in terms of RED reflectance variation. On the other hand, within the RST-FLOOD application, the identification of anomalous "flooded" pixels on the lake border could represent for sure a limitation. The NDSI signal is inherently affected by the increase in the RED signal due to suspended sediments but its implementation within RST did not generate evident signal anomalies, thus indicating that the adoption of the normalized signal coupled with the differential approach enables to face any possible issue.

A possible further limitation that could influence the NDSI signal is the presence of snow, which would produce a spectral signature similar to the flooded areas [7] due to the spectral position of VIIRS I3 band (i.e., 1.58-1.64 $\mu \mathrm{m}$ ). Concerning this issue, at least two possible scenarios can be defined in the RST context, depending on whether the investigated area is characterized by the presence/absence of permanent snow. The RST local (at pixel scale) differential approach allows at overcoming this limitation for the permanent snow-covered areas that, showing all the time very high NDSI value, will not produce any anomalous ALICE values, also in presence of fresh snow. On the other hand, different 
bands combination, such as using the NIR channel in place of the SWIR one, could help to face this issue within the zones characterized by sporadic snow events.

In any case, other test cases should be investigated in the next future to better assess the abovementioned issues as well as to further confirm the quality of the results achieved in this work, considering other environmental scenarios as well as flooding events of a different nature and dynamics. Moreover, it should be stressed that a possible implementation of RST-FLOOD at global scale would require a consistent preliminary work, aimed first at collecting multiple-year time series homogeneous satellite records and then to their analyses in order to produce the reference fields.

Finally, it is worth noting that the proposed approach can also be exported on other VIIRS bands able to detect flooded area due to the differential nature of RST scheme. Thermal Moderate bands

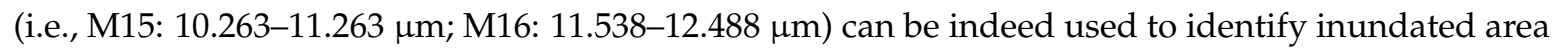
by exploiting the difference in terms of thermal inertia (TI) that these areas should present respect with the unperturbed condition of the surrounding areas [63]. Water shows a higher TI than dry soil and consequently a less capability to change its temperature during the diurnal cycle. Therefore, those areas where soil water content increases because of the flood typically show a reduced diurnal temperature fluctuation compared to the dry conditions, with, in particular, a brightness temperature increase in night-time [64]. This physical property will allow also for a night-time flood detection that will enforce the potential of this sensor in providing near-real time and continuous information about flood dynamics.

In this framework, we have implemented the same approach described in Section 3.3 to analyse the VIIRS M15 image acquired on 4 December 2013 at 00:45, producing the corresponding RST-FLOOD map (Figure 14), where the anomalous pixels in terms of increasing ALICE $\mathrm{TIR}_{\mathrm{TR}}$ values are reported. Although the lower spatial resolution of these data $(750 \mathrm{~m})$ than the Imagery ones, the result is quite impressive, because all the anomalous pixels are located along the rivers in good agreement with the flood hazard map (Figure 4) and they are almost well co-located to the areas already detected (see Figure 10). It is worth noting that ALICE $E_{T I R}$ value higher than 4 were not found and that, in the night-time images of the following days, flooded pixels were detected at ALICE values less than 2, hence resulting no statistically significant. The low spatial resolution of the thermal data, as well as a lower signal intensity in correspondence of flooded areas than the one measured at VNIR wavelengths, is probably at the basis of such a behaviour.

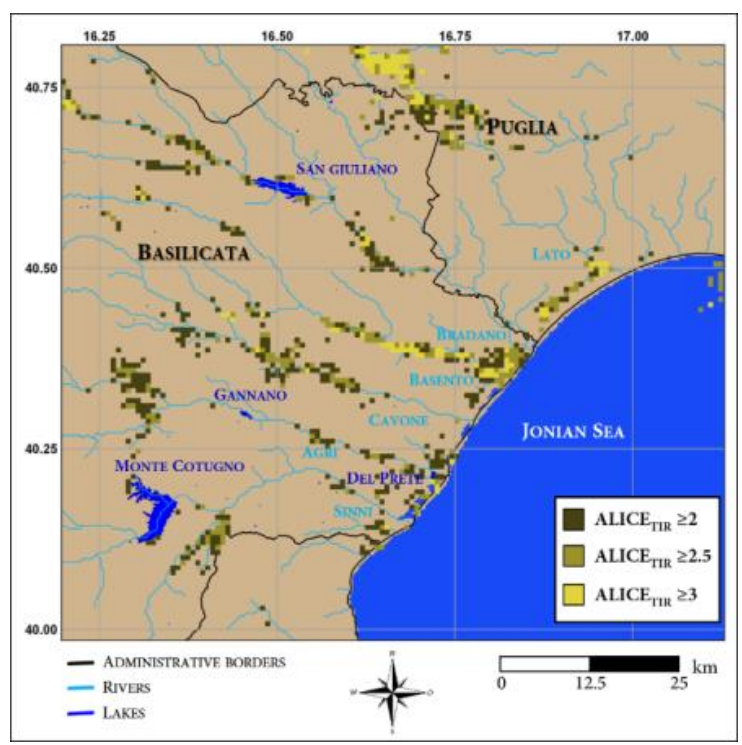

Figure 14. ALICE $E_{T I R}$ map for the VIIRS data of 04/12/2013 at 00:45 GMT. 
Considering that such a VIIRS image has been acquired almost 12 hours before the first diurnal one considered in the previous analysis, the integration of the maps referred to night-time (Figure 14) and daytime (Figure 10) conditions, further extends the investigated temporal domain.

\section{Conclusions}

The RST-FLOOD, a well-established satellite-based approach for flood detection and monitoring, has been fully implemented here for the first time with SNPP-VIIRS data. The event that affected the Metaponto Plain (southern Italy) during the first week of December 2013 has been investigated using such an approach by analysing 171 SNPP orbits, for a total of 684 VIIRS SDR products.

A study aimed at identifying the best signal, among the opportunities assured by the first three VIIRS Imagery bands, has been preliminarily performed identifying the NDSI (I1 - I3/I1 + I3) as the metric with the best trade-off between reliability and sensitivity respect to the investigated event features. Such a signal has been then implemented within the RST-FLOOD approach, through the computation of the ALICE index aimed to investigate the flood dynamics in the 4-8 December 2013 period. The achieved findings demonstrated the good potential of the proposed approach in providing daily reliable indication on the flooding event. Only a residual $11.5 \%$ of possible false positives was recorded when the whole investigated scene was considered, reducing to only $4 \%$ when the area mostly affected by the event was investigated. An anomalous area of about $18 \mathrm{~km}^{2}$, flooded "for sure" accordingly to the outcomes provided by previous works [31,37] as well as of the flood documentations [32-36], was detected by RST-FLOOD outside the flood hazard map, suggesting the need of its updating for better managing future risk, especially considering that an increase in intensity and in frequency of extreme meteo-hydrological events has expect in the next year for the Basilicata region [65]. The comparison with another VIIRS-based method [11], developed to work a global scale, confirmed the reliability of the outputs, suggesting a good capability of RST-FLOOD in detecting flooded area.

Finally, the achieved results demonstrated the potential of medium-resolution optical sensors, like VIIRS, in detecting floods that affect small watersheds, usually investigable only by using data (opticalor microwave-based) at higher spatial resolution [17]. Considering the high temporal resolution offered by VIIRS sensor (that thanks to the recent launch of JPSS-1 has further improved), the relevance of the achieved results become quite evident. The possibility of having continuous and reliable indication about the flood localization and extent may represent a valuable resource for both decision makers and hydrological models. Their assimilation would allow both for an updating of the model set up conditions as well as for a general quality improvement of the results. Finally, their integration with high spatial resolution optical data, such as those acquired by the MultiSpectral Instrument (MSI) aboard European Space Agency (ESA) Sentinel-2 mission, will allow for a more detailed view of the areas affected by the event.

Author Contributions: Conceptualization, T.L. and M.F.; Data curation, T.L., E.C., M.F. and V.S.; Formal analysis, T.L., E.C., M.F. and V.S.; Investigation, T.L. and M.F.; Methodology, T.L., M.F., N.P. and V.T.; Validation, M.F.; Visualization, T.L.; Writing—original draft, T.L. and M.F.; Writing-review \& editing, N.P. and V.T..

Funding: This work has been partly funded in the framework of the MIUR SMART BASILICATA project.

Acknowledgments: We would like to acknowledge the Civil Protection of the Basilicata Region for providing river water level data.

Conflicts of Interest: The authors declare no conflict of interest.

\section{References}

1. Samela, C.; Albano, R.; Sole, A.; Manfreda, S. A GIS tool for cost-effective delineation of flood-prone areas. Comput. Environ. Urban Syst. 2018, 70, 43-52. [CrossRef]

2. Ward, P.J.; de Perez, E.C.; Dottori, F.; Jongman, B.; Luo, T.; Safaie, S.; Uhlemann-Elmer, S. The Need for Mapping, Modeling, and Predicting Flood Hazard and Risk at the Global Scale. In Global Flood Hazard: Applications in Modeling, Mapping, and Forecasting, 1st ed.; Schumann, G.J.-P., Bates, P.D., Apel, H., Aronica, G.T., Eds.; John Wiley \& Sons, Inc.: Hoboken, NJ, USA, 2018; ISBN 978-1-119-21786-2. 
3. Munich, R.E. Topics Geo-Natural Catastrophes 2017. Analyses, Assessments, Positions. 2018. Available online: https:/ / www.munichre.com/site/touch-publications/get/documents_E711248208/mr/assetpool. shared/Documents /5_Touch/_Publications/TOPICS_GEO_2017-en.pdf (accessed on 12 February 2019).

4. Antonioli, F.; Anzidei, M.; Amorosi, A.; Presti, V.L.; Mastronuzzi, G.; Deiana, G.; Marsico, A. Sea-level rise and potential drowning of the Italian coastal plains: Flooding risk scenarios for 2100. Quat. Sci. Rev. 2017, 158, 29-43. [CrossRef]

5. Ward, P.J.; Jongman, B.; Aerts, J.C.J.H.; Bates, P.D.; Botzen, W.J.W.; Diaz, L.A.; Hallegatte, S.; Kind, J.M.; Kwadijk, J.; Scussolini, P.; et al. A global framework for future costs and benefits of river-flood protection in urban areas. Nat. Clim. Chang. 2017, 7, 642-646. [CrossRef]

6. Sun, D.; Li, S.; Zheng, W.; Croitoru, A.; Stefanidis, A.; Goldberg, M. Mapping floods due to Hurricane Sandy using NPP VIIRS and ATMS data and geotagged Flickr imagery. Int. J. Digit. Earth 2016, 9, 427-441. [CrossRef]

7. Huang, C.; Chen, Y.; Zhang, S.; Wu, J. Detecting, extracting, and monitoring surface water from space using optical sensors: A review. Rev. Geophys. 2018, 56, 333-360. [CrossRef]

8. Schumann, G.P.; Brakenridge, G.R.; Kettner, A.J.; Kashif, R.; Niebuhr, E. Assisting Flood Disaster Response with Earth Observation Data and Products: A Critical Assessment. Remote Sens. 2018, 10, 1230. [CrossRef]

9. Markert, K.L.; Chishtie, F.; Anderson, E.R.; Saah, D.; Griffin, R.E. On the merging of optical and SAR satellite imagery for surface water mapping applications. Results Phys. 2018, 9, 275-277. [CrossRef]

10. Dasgupta, A.; Grimaldi, S.; Ramsankaran, R.; Pauwels, V.R.N.; Walker, J.P.; Chini, M.; Hostache, R.; Matgen, P. Flood Mapping Using Synthetic Aperture Radar Sensors from Local to Global Scales. In Global Flood Hazard: Applications in Modeling, Mapping, and Forecasting, Geophysical Monograph 233, 1st ed.; John Wiley \& Sons, Inc.: Hoboken, NJ, USA, 2018; ISBN 978-1-119-21786-2.

11. Li, S.; Sun, D.; Goldberg, M.D.; Sjoberg, B.; Santek, D.; Hoffman, J.P.; DeWeese, M.; Restrepo, P.; Lindsey, S.; Holloway, E. Automatic near real-time flood detection using Suomi-NPP/VIIRS data. Remote Sens. Environ. 2018, 204, 672-689. [CrossRef]

12. The International Charter Space and Major Disasters. Available online: https://disasterscharter.org/web/ guest/home (accessed on 12 February 2019).

13. Copernicus Emergency Management Service. Available online: https://emergency.copernicus.eu/ (accessed on 12 February 2019).

14. Lacava, T.; Ciancia, E.; Faruolo, M.; Pergola, N.; Satriano, V.; Tramutoli, V. Analyzing the December 2013 Metaponto Plain (Southern Italy) Flood Event by Integrating Optical Sensors Satellite Data. Hydrology 2018, 5, 43. [CrossRef]

15. Fayne, J.; Bolten, J.; Lakshmi, V.; Ahamed, A. Optical and Physical Methods for Mapping Flooding with Satellite Imagery. In Remote Sensing of Hydrological Extremes; Springer Remote Sensing/Photogrammetry; Lakshmi, V., Ed.; Springer International Publishing: Basel, Switzerland, 2017; Chapter 5; pp. 83-103. [CrossRef]

16. Kwak, Y. Nationwide Flood Monitoring for Disaster Risk Reduction Using Multiple Satellite Data. ISPRS Int. J. Geo-Inf. 2017, 6, 203. [CrossRef]

17. Ogilvie, A.; Belaud, G.; Massuel, S.; Mulligan, M.; Le Goulven, P.; Calvez, R. Surface water monitoring in small water bodies: Potential and limits of multi-sensor Landsat time series. Hydrol. Earth Syst. Sci. 2018, 22, 4349-4380. [CrossRef]

18. Lacava, T.; Ciancia, E.; Coviello, I.; Di Polito, C.; Faruolo, M.; Pergola, N.; Satriano, V.; Tramutoli, V. A Satellite Multi-Sensor Approach For Flooded Areas Detection and Monitoring. Adv. Watershed Hydrol. 2015, 51, 83-96.

19. Brakenridge, G.R. Flood Risk Mapping from Orbital Remote Sensing. In Global Flood Hazard: Applications in Modeling, Mapping, and Forecasting, 1st ed.; Schumann, G.J.-P., Bates, P.D., Apel, H., Aronica, G.T., Eds.; John Wiley \& Sons, Inc.: Hoboken, NJ, USA, 2018; ISBN 978-1-119-21786-2.

20. Normandin, C.; Frappart, F.; Lubac, B.; Bélanger, S.; Marieu, V.; Blarel, F.; Robinet, A.; Guiastrennec-Faugas, L. Quantification of surface water volume changes in the Mackenzie Delta using satellite multi-mission data. Hydrol. Earth Syst. Sci. 2018, 22, 1543-1561. [CrossRef]

21. Tramutoli, V. Robust Satellite Techniques (RST) for Natural and Environmental Hazards Monitoring and Mitigation: Theory and Applications. In Proceedings of the Fourth International Workshop on the Analysis of Multitemporal Remote Sensing Images, Louven, Belgium, 18-20 July 2007. [CrossRef] 
22. Lacava, T.; Filizzola, C.; Pergola, N.; Sannazzaro, F.; Tramutoli, V. Improving flood monitoring by the Robust AVHRR Technique (RAT) approach: The case of the April 2000 Hungary flood. Int. J. Remote Sens. 2010, 31, 2043-2062. [CrossRef]

23. Faruolo, M.; Coviello, I.; Lacava, T.; Pergola, N.; Tramutoli, V. A multi-sensor exportable approach for automatic flooded areas detection and monitoring by a composite satellite constellation. IEEE Trans. Geosci. Remote Sens. 2013, 51, 2136-2149. [CrossRef]

24. Imbrenda, V.; D’Emilio, M.; Lanfredi, M.; Macchiato, M.; Ragosta, M.; Simoniello, T. Indicators for the estimation of vulnerability to land degradation derived from soil compaction and vegetation cover. Eur. J. Soil Sci. 2014, 65, 907-923. [CrossRef]

25. Imbrenda, V.; Coluzzi, R.; Lanfredi, M.; Loperte, A.; Satriani, A.; Simoniello, T. Analysis of landscape evolution in a vulnerable coastal area under natural and human pressure. Geomat. Nat. Hazards Risk 2018. [CrossRef]

26. Autorità di Bacino della Basilicata. Mappe della Pericolosità e Mappe del Rischio Idraulico, Relazione 2014. Available online: http:/ / www.adb.basilicata.it/adb/Pstralcio/pianoacque/Relazione_ottobre_2014.pdf (accessed on 12 February 2019).

27. Autorità di Bacino della Basilicata. Capitolo IV, Disponibilità: Le Acque superficiali. 2016. Available online: http:/ / www.adb.basilicata.it/adb/pstralcio/bilancioidrico/cap4.pdf (accessed on 12 February 2019).

28. Centro Funzionale Decentrato della Protezione Civile Basilicata. Dati in Tempo Reale-Pluviometria. 2018. Available online: http:/ / centrofunzionalebasilicata.it/it/sensoriTempoReale.php?st=I (accessed on 12 February 2019).

29. Dal Sasso, S.F.; Cantisani, A.; Lanorte, V.; Pacifico, G.; Manfreda, S. Gli eventi storici della Basilicata. In Le Precipitazioni Estreme in Basilicata, 1st ed.; Manfreda, S., Sole, A., De Costanzo, G., Eds.; Universosud Società Cooperativa: Potenza, Italy, 2015; pp. 6-24. ISBN 978-88-99432-03-4. Available online: http:/ /www. centrofunzionalebasilicata.it/it/pdf/pioggia_download.pdf (accessed on 12 February 2019).

30. Di Polito, C.; Ciancia, E.; Coviello, I.; Doxaran, D.; Lacava, T.; Pergola, N.; Satriano, V.; Tramutoli, V. On the Potential of Robust Satellite Techniques Approach for SPM Monitoring in Coastal Waters: Implementation and Application over the Basilicata Ionian Coastal Waters Using MODIS-Aqua. Remote Sens. 2016, 8, 922. [CrossRef]

31. D'Addabbo, A.; Refice, A.; Pasquariello, G.; Lovergine, F.P.; Capolongo, D.; Manfreda, S. A Bayesian network for flood detection combining SAR imagery and ancillary data. IEEE Trans. Geosci. Remote Sens. 2016, 54, 3612-3625. [CrossRef]

32. Centro Funzionale Decentrato della Protezione Civile Basilicata. Eventi Metereologici Eccezionali dei Giorni 1, 2 e 3 Dicembre 2013 nel territorio della Regione Basilicata. 2013. Available online: http:/ / www. centrofunzionalebasilicata.it/ew/ew_pdf/r/Report\%20evento\%20dicembre\%202013.pdf (accessed on 12 February 2019).

33. Autorità di Bacino della Puglia. Valutazione Globale Provvisoria del Piano di Gestione del Rischio di Alluvioni. 2015. Available online: http:/ / www.adb.puglia.it/public/files/downloads/20151104_PGRA/ VGP.pdf (accessed on 12 February 2019).

34. Centro Funzionale Decentrato della Protezione Civile Puglia. Rapporto D'evento: Evento MeteoIdropluviometrico del 30 Novembre-3 Dicembre 2013. 2014. Available online: http:/ / www.protezionecivile. puglia.it/archives/2244 (accessed on 12 February 2019).

35. Il Giornale della Protezione Civile Rassegna Stampa del 4/12/2013. 2013. Available online: https:/ / www. ilgiornaledellaprotezionecivile.it/html/download.html?id=7315738794M (accessed on 12 February 2019).

36. MeteoWeb. Maltempo, Esonda il Fiume Lato nel Tarantino: Case in Pericolo a Castellaneta Marina. 2013. Available online: http:/ / www.meteoweb.eu/2013/12/maltempo-esonda-il-fiume-lato-nel-tarantino-casein-pericolo-a-castellaneta-marina/244468/\#LL1PsEgcYY9bjUwO.99 (accessed on 12 February 2019).

37. De Musso, N.M.; Capolongo, D.; Refice, A.; Lovergine, F.P.; D’Addabbo, A.; Pennetta, L. Spatial evolution of the December 2013 Metaponto plain (Basilicata, Italy) flood event using multi-source and high-resolution remotely sensed data. J. Maps 2018, 14, 219-229. [CrossRef]

38. Joint Polar Satellite System (JPSS). JPSS-1 has a New Name: NOAA-20. 2017. Available online: http: / /www.jpss.noaa.gov/launch.html (accessed on 12 February 2019). 
39. National Environmental Satellite, Data, and Information Service (NESDIS). Polar Satellite Programs Continuity of Weather Observations. 2018. Available online: https://www.nesdis.noaa.gov/sites/ default/files/asset/document/Polar_Flyout\%20Jan_2018_Weather_Signed_Linked.pdf (accessed on 12 February 2019).

40. Cao, C.; Xiong, J.; Blonski, S.; Liu, Q.; Uprety, S.; Shao, X.; Bai, Y.; Weng, F. Suomi NPP VIIRS sensor data record verification, validation, and long-term performance monitoring. J. Geophys. Res. Atmos. 2013, 118, 664-678. [CrossRef]

41. NOAA Comprehensive Large Array-data Stewardship System (CLASS). 2019. Available online: https: / / www.avl.class.noaa.gov/saa/products/welcome (accessed on 12 February 2019).

42. Polar2Grid, 2018. Available online: https://www.ssec.wisc.edu/software/polar2grid/\# (accessed on 12 February 2019).

43. Geoportale Nazionale-Ministero dell'Ambiente e della Tutela del Territorio e del Mare. 2018. Available online: http:/ / www.pcn.minambiente.it/mattm/direttiva-alluvioni/ (accessed on 12 February 2019).

44. Community Satellite Processing Package (CSPP). Suomi-NPP VIIRS Flood Detection Software Version 1.0 Release. 2018. Available online: http:/ / cimss.ssec.wisc.edu/cspp/viirs_flood_v1.0.shtml (accessed on 12 February 2019).

45. USGS Earth Explorer. Available online: https:/ / earthexplorer.usgs.gov/ (accessed on 12 February 2019).

46. Quinn, J.W. Landsat Band Combination. Available online: http://web.pdx.edu/ emch/ip1/ bandcombinations.html (accessed on 12 February 2019).

47. USGS Landsat Missions. Available online: https://landsat.usgs.gov/known-issues (accessed on 12 February 2019).

48. Sole, A.; Giosa, L.; Copertino, V. Risk flood areas, a case study: Basilicata Region. WIT Trans. Ecol. Environ. 2017, 104, 213-228. Available online: https://www.witpress.com/Secure/elibrary/papers/RM07/ RM07021FU1.pdf (accessed on 12 February 2019). [CrossRef]

49. Tramutoli, V. Robust AVHRR Techniques (RAT) for Environmental Monitoring: Theory and applications. Earth Surface Remote Sensing II, Giovanna Cecchi, Eugenio Zilioli, Editors. Proc. SPIE 1998, 3496, 101-113.

50. Ciancia, E.; Coviello, I.; Di Polito, C.; Lacava, T.; Pergola, N.; Satriano, V.; Tramutoli, V. Investigating the chlorophyll-a variability in the Gulf of Taranto (North-western Ionian Sea) by a multi-temporal analysis of MODIS-Aqua Level 3/Level 2 data. Cont. Shelf Res. 2018, 155, 34-44. [CrossRef]

51. Koeppen, W.C.; Pilger, E.; Wright, R. Time series analysis of infrared satellite data for detecting thermal anomalies: A hybrid approach. Bull. Volcanol. 2011, 73, 577-593. [CrossRef]

52. Cuomo, V.; Filizzola, C.; Pergola, N.; Pietrapertosa, C.; Tramutoli, V. A self-sufficient approach for GERB cloudy radiance detection. Atmos. Res. 2004, 72, 39-56. [CrossRef]

53. Pietrapertosa, C.; Pergola, N.; Lanorte, V.; Tramutoli, V. Self Adaptive Algorithms for Change Detection: OCA (the One-channel Cloud-detection Approach) an adjustable method for cloudy and clear radiances detection. In Proceedings of the Technical Proceedings of the Eleventh International (A)TOVS Study Conference (ITSC-XI), Budapest, Hungary, 20-26 September 2000; pp. 281-291.

54. Huang, C.; Chen, Y.; Wu, J.; Li, L.; Liu, R. An evaluation of Suomi NPP-VIIRS data for surface water detection. Remote Sens. Lett. 2015, 6, 155-164. [CrossRef]

55. Xiao, X.G.; Shen, Z.X.; Qin, X.G. Assessing the potential of vegetation sensor data for mapping snow and ice cover: A Normalized Difference Snow and Ice Index. Int. J. Remote Sens. 2001, 22, 2479-2487. [CrossRef]

56. Boschetti, M.; Nutini, F.; Manfron, G.; Brivio, P.A.; Nelson, A. Comparative Analysis of Normalised Difference Spectral Indices Derived from MODIS for Detecting Surface Water in Flooded Rice Cropping Systems. PLoS ONE 2014, 9, e88741. [CrossRef]

57. Piper, M.; Bahr, T. A rapid cloud mask algorithm for SUOMI NPP VIIRS imagery EDRS. The International Archives of the Photogrammetry, Remote Sensing and Spatial Information Sciences. In Proceedings of the 36th International Symposium on Remote Sensing of Environment, Berlin, Germany, 11-15 May 2015; Volume XL-7/W3.

58. Candra, D.S.; Phinn, S.; Scarth, P. Cloud and cloud shadow masking using multi-temporal cloud masking algorithm in tropical environmental. The International Archives of the Photogrammetry, Remote Sensing and Spatial Information Sciences. In Proceedings of the XXIII ISPRS Congress, Prague, Czech Republic, 12-19 July 2016; Volume XLI-B2. [CrossRef] 
59. Zhu, Z.; Woodcock, C.E. Object-based cloud and cloud shadow detection in Landsat imagery. Remote Sens. Environ. 2012, 118, 83-94. [CrossRef]

60. Sanyal, J.; Lu, X.X. Application of Remote Sensing in Flood Management with Special Reference to Monsoon Asia: A Review. Nat. Hazards 2014, 33, 283-301. [CrossRef]

61. Franci, F.; Mandanici, E.; Bitelli, G. Remote sensing analysis for flood risk management in urban sprawl contexts. Geomat. Nat. Hazards Risk 2015, 6, 583-599. [CrossRef]

62. Lacava, T.; Brocca, L.; Coviello, I.; Faruolo, M.; Pergola, N.; Tramutoli, V. Integration of optical and passive microwave satellite data for flooded area detection and monitoring. In Engineering Geology for Society and Territory; Springer International Publishing: Basel, Switzerland, 2014; Volume 3, pp. 631-635. [CrossRef]

63. Tramutoli, V.; Claps, P.; Marella, M.; Pergola, N.; Sileo, C. Feasibility of hydrological application of thermal inertia from remote sensing. In Proceedings of the 2nd Plinius Conference on Mediterranean Storms, Siena, Italy, 16-18 October 2000; pp. 16-18.

64. Verstraeten, W.W.; Veroustraete, F.; van der Sande, C.J.; Grootaers, I.; Feyen, J. Soil moisture retrieval using thermal inertia, determined with visible and thermal spaceborne data validated for European forests. Remote Sens. Environ. 2006, 101, 299-314. [CrossRef]

65. Piccarreta, M.; Pasini, A.; Capolongo, D.; Lazzari, M. Changes in daily precipitation extremes in the Mediterranean from 1951 to 2010: The Basilicata region, Southern Italy. Int. J. Climatol. 2013, 33, 3229-3248. [CrossRef]

(C) 2019 by the authors. Licensee MDPI, Basel, Switzerland. This article is an open access article distributed under the terms and conditions of the Creative Commons Attribution (CC BY) license (http:/ / creativecommons.org/licenses/by/4.0/). 